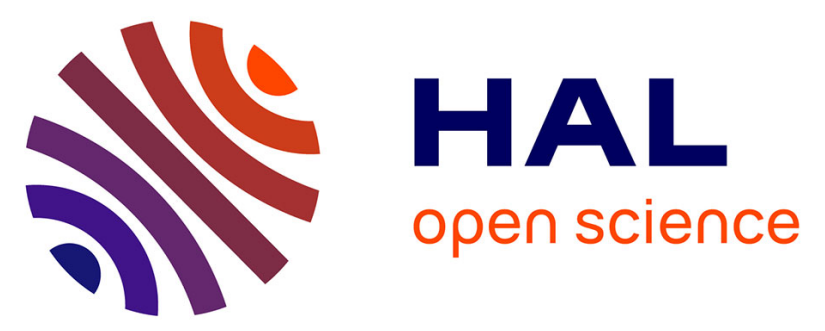

\title{
Real time monitoring of the quiescent suspension copolymerization of vinyl chloride with methyl methacrylate in microreactors - Part 3. A kinetic study by raman spectroscopy and evolution of droplet size
}

\author{
C. A. Castor Jr., Alain Pontier, Jérôme J. Durand, J. C. Pinto, Laurent Prat
}

\section{- To cite this version:}

C. A. Castor Jr., Alain Pontier, Jérôme J. Durand, J. C. Pinto, Laurent Prat. Real time monitoring of the quiescent suspension copolymerization of vinyl chloride with methyl methacrylate in microreactors - Part 3. A kinetic study by raman spectroscopy and evolution of droplet size. Chemical Engineering Science, 2017, 173, pp.493-506. 10.1016/j.ces.2017.08.018 . hal-01939182

\section{HAL Id: hal-01939182 \\ https://hal.science/hal-01939182}

Submitted on 24 May 2019

HAL is a multi-disciplinary open access archive for the deposit and dissemination of scientific research documents, whether they are published or not. The documents may come from teaching and research institutions in France or abroad, or from public or private research centers.
L'archive ouverte pluridisciplinaire HAL, est destinée au dépôt et à la diffusion de documents scientifiques de niveau recherche, publiés ou non, émanant des établissements d'enseignement et de recherche français ou étrangers, des laboratoires publics ou privés. 


\section{OATAO \\ Open Archive Toulouse Archive Ouverte}

\section{Open Archive Toulouse Archive Ouverte (OATAO)}

OATAO is an open access repository that collects the work of Toulouse researchers and makes it freely available over the web where possible

This is an author's version published in: http://oatao.univ-toulouse.fr/20404

Official URL: https://doi.org/10.1016/j.ces.2017.08.018

\section{To cite this version:}

Castor Junior, Carlos Alberto and Pontier, Alain Durand, Jérôme ${ }^{\mathrm{J}}$ and Pinto, José Carlos Costa Da Silva and Prat, Laurent E.DReal time monitoring of the quiescent suspension copolymerization of vinyl chloride with methyl methacrylate in microreactors - Part 3. A kinetic study by raman spectroscopy and evolution of droplet size. (2017) Chemical Engineering Science, 173. 493-506. ISSN 00092509

Any correspondence concerning this service should be sent to the repository administrator: tech-oatao@listes-diff.inp-toulouse.fr 


\title{
Real time monitoring of the quiescent suspension copolymerization of vinyl chloride with methyl methacrylate in microreactors - Part 3. A kinetic study by raman spectroscopy and evolution of droplet size
}

\author{
C.A. Castor Jr ${ }^{\mathrm{a}, *}$, A. Pontier ${ }^{\mathrm{b}}$, J. Durand ${ }^{\mathrm{c}}$, J.C. Pinto ${ }^{\mathrm{a}}$, L. Prat ${ }^{\mathrm{b}}$ \\ a Programa de Engenharia Química (PEQ/COPPE), Universidade Federal do Rio de Janeiro, Rio de Janeiro, 21841-972 RJ, Brazil \\ ${ }^{\mathrm{b}}$ Laboratoire de Génie Chimique (LGC UMR 5503), Université de Toulouse, INPT, ENSIACET, 4 allée Emile Monso, BP 84234, F-31432 Toulouse, France \\ ${ }^{\mathrm{c}}$ Laboratoire de Chimie de Coordination (UPR CNRS 8241), Université de Toulouse, INPT, ENSIACET, 4 allée Emile Monso-CS 44362, 31030 Toulouse, France
}

\section{H I G H L I G H T S}

- Experimental work on the suspension copolymerization of VCM with MMA by using microreactors.

- The reaction kinetics was monitored by Raman spectroscopy.

- Evolution of the particle volumes was monitored and correlated to monomer conversion.

- Performances between bifunctional and monofunctional initiators were compared.

- A new mechanism based on the results from both video camera and Raman spectroscopy is proposed.
G R A P H I C A L A B S T R A C T

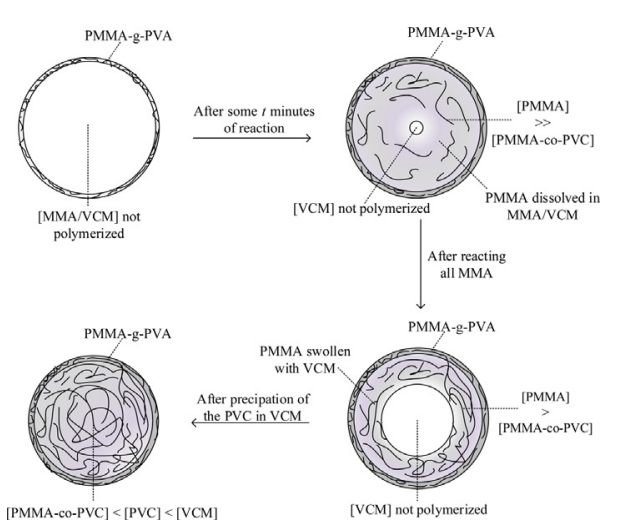

A B S T R A C T

The present work presents results on the copolymerization kinetics of methyl methacrylate (MMA) and vinyl chloride (VCM) monitored by Raman spectroscopy and on the evolution of droplets as captured by charge-coupled device (CCD) camera in a microcapillary reactor. Different experimental recipes were proposed using commercial initiators in order to compare the system performance when initiated with monofunctional and bifunctional peroxides. The experimental setup was able to capture the distinct stages of the copolymerization within a microreactor up to high conversions $(>90 \%)$ in quiescent state. It is shown that the copolymerization of MMA with VCM leads to distinct morphological structures, when compared to VCM homopolymerization, forming a core and a shell after a certain critical conversion. A new mechanism is proposed for the copolymerization based on the results from both video camera and Raman spectroscopy.
Keywords:

Microreactors

Suspension copolymerization

Raman spectroscopy

Kinetics

Vinyl chloride

Methyl methacrylate

\section{Introduction}

The usage of microreactors has increased steadily in the chemical engineering field (Jensen, 2001; Pattekar and Kothare, 2004;

\footnotetext{
* Corresponding author.

E-mail address: carlosche@peq.coppe.ufrj.br (C.A. Castor Jr).
}

Sun et al., 2008; Chang et al., 2004; Iwasaki and Yoshida, 2005; Richard et al., 2013) and in other areas of study (Zhang et al., 2004; Salic et al., 2012; Massignani et al., 2010). The application of this technology has been proposed originally to allow for small-scale production and became a reality in the late 1980 s and early 1990s (Benson and Ponton, 1993). In order to provide higher flexibility and allow for assessment of the capacity, safety 
and variability of the real process in a realistic way, microreactors should be regarded as complementary apparatuses for other existing large-scale facilities (Lerou et al., 1996; Wegeng et al., 1996). It is important to emphasize that microreactors may exhibit characteristic dimensions of the order of millimeters and sub-millimeter (Pattekar and Kothare, 2004; Richard et al., 2013).

Microreactors find potential use in many applications, including biocatalysis (Fernandes, 2010), biodiesel production (Sun et al., 2008; Richard et al., 2013), heterogeneous catalysis (KiwiMinsker and Renken, 2005), drug synthesis (Kang et al., 2008; Leroyer et al., 2013), hydrogen production (Pattekar and Kothare, 2004), photocatalysis (Gorges et al., 2004) and polymerization processes (Bodoc et al., 2012; Bally et al., 2010; Castor et al., 2015, 2016; Mahadevan et al., 2016). Following the general principles of the Green Chemistry, microreactors can be used to synthesize and purify organometallic compounds by atomic layer deposition (ALD) and chemical vapor deposition (CVD), allowing for safe operations and production of chemicals with higher degree of purity (Lipiecki et al., 2008, 2009).

Few studies have examined the free radical copolymerization of VCM in the literature. Tables 1 and 2 show the main patents and papers, respectively, regarding both mass and suspension copolymerization of vinyl chloride. It is worth mentioning that almost $81 \%$ of the PVC world production is based on suspension polymerization processes (Anon, 2011). Table 1 also highlights processes copolymerizations with some comonomers such as methyl methacrylate, acrylic acid esters and maleic anhydride. From Table 2 it becomes clear that the elasticity properties of the PVC have been improved when some particular comonomers are used,

Table 1

Comonomers used in some patents to both mass and suspension polymerization based on vinyl chloride.

\begin{tabular}{lcc}
\hline Comonomers & $\begin{array}{c}\text { Polymerization } \\
\text { Processes }\end{array}$ & Authors \\
\hline VCM/propylene-ethylene & Suspension & Müllner and Albert \\
& Suspension & Kamio et al. (1970) \\
VCM/ethylene & Suspension & Williams (1970) \\
MMA-g-PVC & Mass and Suspension & SOLVAY (1971) \\
VCM/epichloridryn & Suspension & Yonkers et al. (1971) \\
VCM/vinyl actetate & Suspension & Reiter and Reventas \\
poly(ethylene) in VCM & & $(1973)$ \\
& Mass and Suspension & Kitamura et al. (1973) \\
VCM/ester monomers & Suspension & SOLVAY (1975) \\
VCM/esters of acid acrylic & Suspension & Sielfeld (1984) \\
VCM/poly(vinyl isobutyl & Suspension & Martyak (2010) \\
ether) & & \\
VCM/maleic anhydride & &
\end{tabular}

Table 2

Comonomers used in some papers of both mass and suspension VCM-based polymerizations.

\begin{tabular}{lcc}
\hline Comonomers & $\begin{array}{c}\text { Polymerization } \\
\text { processes }\end{array}$ & Authors \\
\hline $\begin{array}{l}\text { VCM/vinyl acetate } \\
\text { VCM/vinyl acetate }\end{array}$ & $\begin{array}{c}\text { Mass } \\
\text { Suspension }\end{array}$ & $\begin{array}{c}\text { Marvel et al. (1942) } \\
\text { Emmer and Bankoff } \\
\text { (1954) }\end{array}$ \\
VCM/vinyl esters & Suspension & Port et al. (1955) \\
VCM/MMA & Mass & McNeill and Straiton \\
poli(butyl acrylate) in VCM & Mass & Walsh and Cheng \\
VCM/butyl acrylate & Suspension & Macho et al. (1998) \\
VCM/ethylene glycol & Suspension & Yong-Zhong et al. \\
dimethacrylate & Suspension & Bichuch et al. (2003) \\
VCM/MMA & Suspension & Yuan et al. (2007) \\
poly(butyl acrylate) in VCM & & \\
\hline
\end{tabular}

as reported by Kitamura et al. (1973) and Yong-Zhong et al. (2000), who also used a multifunctional monomer ethylene glycol dimethacrylate.

The applications of VCM-based copolymers and their characteristics are determined by the chemical nature of the comonomer (Flory, 1953) and their relative the comonomer concentration in the polymer chains. Attempts to cover a wider range of properties of PVC based products certainly involve molar mass changes, which can lead either to a material with difficult processing characteristics (high molar masses/k values) or to a fragile material (low molar masses/k values) (Burgess, 2005).

Copolymerization of VCM also provide a method for suppressing the formation of anomalous units of the vinyl chloride homopolymer chains. Anomalous entities are formed through rearrangements of the living radical during the reaction. If the cross-propagation step is faster than the isomerization of the living radical, the formation of anomalous structures can be suppressed in the copolymerization systems (Nass and Leonard, 1998).

Müllner and Albert (1967) studied the VCM-propylene copolymerization, and pointed out the difficulty to produce these copolymers with high molar masses due to the high transfer rate to the propylene. In addition, chains with high concentration of propylene are also hard to produce because of the low reactivity between propylene and VCM, producing low reaction rates. Burgess (2005) showed that in order to achieve a propylene concentration of $7.5 \%$ in the final copolymer, it would be necessary to use $34 \%$ of propylene in the initial mixture with VCM.

By far the most important commercially VCM-based copolymer is based on copolymerization with vinyl acetate (VAc), especially in bulk and solution polymerization processes (Marvel et al., 1942). One of the main functions of VAc is reducing the viscosity of the final polymer at the expense of smaller "softening point" and, to a lesser extent, worse thermal stability and worse strength of the material. $\mathbf{k}$ values usually produced in various compositions are between 40 and 55 (Burgess, 2005; Emmer and Bankoff, 1954), which makes the processing of the copolymer easier.

Bichuch et al. (2003) reported some specific characteristics of the PMMA-PVC copolymer obtained by free radical suspension polymerization, by using a mixture of organic peroxide initiators (lauroyl peroxide with $\mathrm{Di}$-(2-ethylhexyl) peroxydicarbonate). The experimental strategy used by such authors was focused on the feed of small quantities of MMA throughout the reaction course because of the decelerating effect of MMA in the reaction, with low rates of copolymerization (composition of monomer mixture equal to $95 \%$ of VCM and 5\% of MMA), when compared to the production of homopolymers in the same experimental conditions. According to the these authors, the $\mathbf{k}$-values of the copolymers decrease as the MMA concentration increases (1-20 wt\%).

The usage of microreactor to perform copolymerization reactions is relatively recent. Bayer et al. (2000) were described advantages of the microreactor technology in the engineer of polymerization reactions. These authors (Bayer et al., 2000) showed that molar mass distributions are narrower in the experiments carried out in microreactors in comparison to those in macroreactors, possibly because of the more homogeneous reaction conditions and better heat transfer rates. Nielsen et al. (2002) carried out the copolymerization of ethylene with 1octene, among others reactions, in a microcapillary reactor of $200 \mu$ l equipped with an electric heating system.

It is also important to report that the use of commercial peroxide multifunctional initiators in free radical polymerizations are restricted to reaction temperatures above $90^{\circ} \mathrm{C}$ (Benbachir and Benjelloun, 2001; Cerna et al., 2002; Fityani-Trimm et al., 2003; Sheng et al., 2004; Scorah et al., 2004; Galhardo et al., 2013; Soljic et al., 2009). Besides, no previous published material reported the use of peroxide multifunctional initiators to produce 
PVC-based copolymers through any polymerization process (mass, solution, emulsion and suspension).

In previous studies, Castor et al. (2015) and Castor et al. (2016) showed that it is possible to monitor the homopolymerization of methyl methacrylate and vinyl chloride droplets in aqueous phase inside microreactors by combining two techniques: Raman spectroscopy and charge-coupled devices (CCD) microscopy. It was also shown that CCD technique makes possible the analysis of the reaction kinetics through monitoring of the evolution of the suspended droplets in quiescent state in microreactors. Based on the previous results, the present work focuses on monitoring the reaction kinetics and the droplet evolution during the suspension copolymerization of methyl methacrylate and vinyl chloride performed at high pressure in microreactors. Raman spectroscopy was used to monitor the kinetics the polymerization, while a high speed CCD video camera was used to monitor the evolution of droplets during the polymerization reactions. The primary objective of study was to investigate the feasibility of using the Raman spectroscopy to characterize the copolymerization kinetics in microreactors at different experimental conditions.

\section{Experimental section}

\subsection{Materials}

All reagents were used as received. Double-deionized water was used throughout the work. The vinyl chloride monomer stabilized with $1 \mathrm{ppm}$ of hydroquinone was supplied by Sigma-Aldrich. The methyl methacrylate monomer stabilized with 20 ppm of hydroquinone was supplied by Sigma-Aldrich. Nitrogen gas $\left(\mathrm{N}_{2}\right)$ was supplied by Air Liquide as an ultra-pure gas and used to keep the inert atmosphere. Poly(vinyl alcohol) (PVA) with degree of hydrolysis of $89 \%$ and weight-average molar mass of $79,000 \mathrm{~g} / \mathrm{mol}$ was used as the suspending agent and was supplied by SigmaAldrich. The peroxide initiators used to perform the polymerization reactions were dilauroyl peroxide (LPO) (minimum purity of $97 \%$, supplied by Sigma-Aldrich), benzoyl peroxide (BPO) (minimum purity of $75 \%$ and containing $25 \%$ of water, supplied by SigmaAldrich) and 2,5-dimethyl-2,5-di(2-ethylhexanoylperoxy) hexane (Trigonox 141) (minimum purity of 92\%, supplied by Akzo Nobel). Acetone with minimum purity of $99.5 \%$ was supplied by SigmaAldrich and used to clean vessels and tubes. Tetrahydrofuran (THF) was used as the mobile phase for GPC analyses and was supplied by VETEC Fine Chemicals as a P.A. solvent.

\subsection{Experimental apparatus}

The same experimental apparatus described by Castor et al. $(2015,2016)$ was used in this paper. Microreactions were conducted in the experimental setup shown in Fig. 1. The components exposed to VCM, such as tubing and valves (Swagelok), were all made of stainless steel. Aqueous phase and VCM flow rates were ensured by Cetoni $\mathrm{GmbH}$ high pressure syringe pumps equipped with high-pressure stainless-steel syringes. The microreactor consisted of fused-silica capillary tubes inserted into a hollow metal block. The metal block was filled with silicone oil and heated from inside by circulating hot oil provided by a thermal bath. At the end of the microreactor setup, a waste vessel was connected to the output line in order to collect the polymerization products and also control the desired back pressure.

The aqueous phase and the organic phase were put in contact with a co-axial generation device, as already shown in previous works (Castor et al., 2015, 2016). The copolymerization of MMA with VCM must be performed in a pressurized system, since vinyl chloride is a gas at ambient temperature, so that the microreactor setup was designed to allow for the maximum working pressure of 30 bar. Aqueous phase and VCM flows were ensured by high pressure syringe pumps equipped with high-pressure stainless-steel syringes.

\subsection{Experimental procedure}

For suspension copolymerization reactions, the apparatus was first purged with nitrogen to avoid any inhibition effect by oxygen. In all experiments described in the present work, the solubilization of initiator in solutions of vinyl chloride with methyl methacrylate was carried out into the syringe pump. The comonomer solution was pumped into the microreactor in order to disperse the organic phase into the aqueous phase. The remaining experimental procedures were conducted exactly as reported in previous works (Bodoc et al., 2012; Castor et al., 2015, 2016). At the end of each experiment, the experimental setup was cleaned with acetone.

A set of copolymerization reactions was carried out according to the experimental conditions presented in Table 3. The concentration of PVA in the aqueous phase was kept constant in all reactions and equal to $0.3 \mathrm{wt} \%$. The main goal of this set of reactions was to evaluate the reaction kinetics with the help of the Raman technique and to compare the performances obtained with different MMA and bifunctional initiator (T141) concentrations in respect

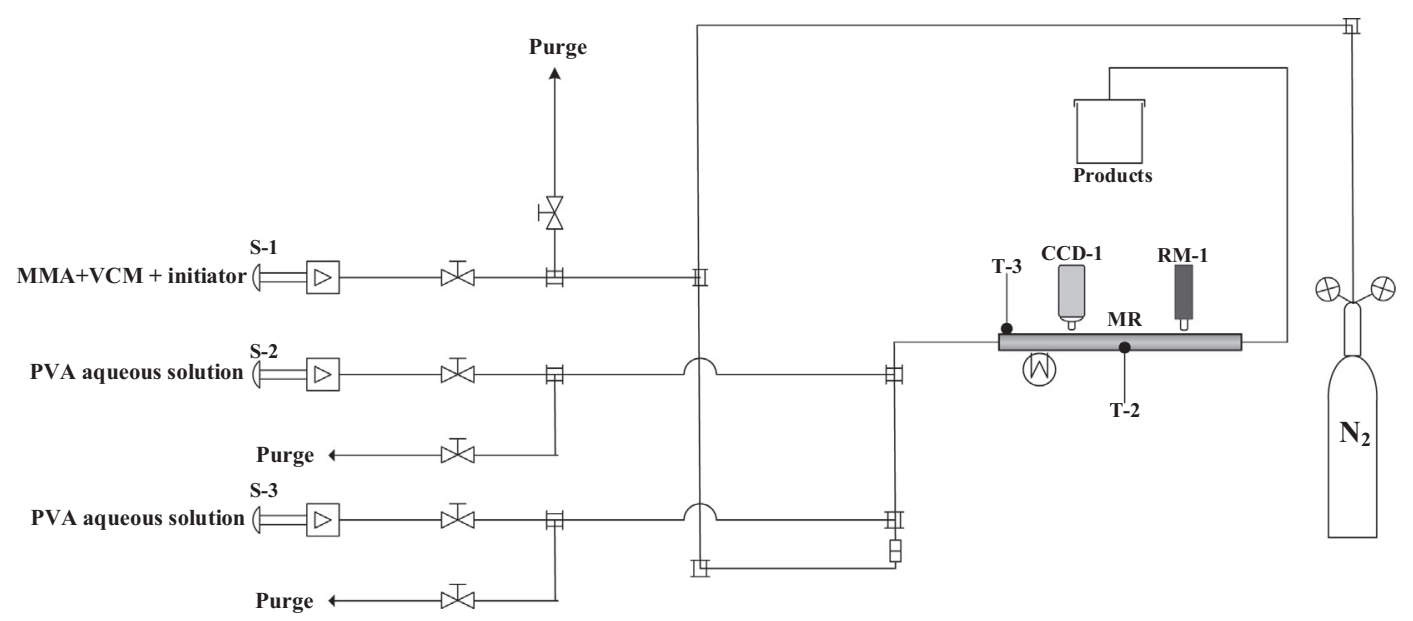

Fig. 1. Microreactor setup used for monitoring the copolymerization of MMA with VCM by Raman spectroscopy and video camera techniques. 
Table 3

Recipes used to perform copolymerization reactions of VCM with MMA in the microreactor.

\begin{tabular}{cccccc}
\hline Experiment & $\begin{array}{c}{[\mathrm{VCM}]} \\
\text { (wt\%) }\end{array}$ & $\begin{array}{c}{[\mathrm{MMA}]} \\
(\mathrm{wt} \%)\end{array}$ & Initiator & $\begin{array}{c}\text { Concentration } \\
(\text { wt } \%)\end{array}$ & $\begin{array}{c}\text { Temperature } \\
\left({ }^{\circ} \mathrm{C}\right)\end{array}$ \\
\hline E1 & 95 & 5 & T141 & 0.29 & 65 \\
E2 & 95 & 5 & T141 & 0.29 & 70 \\
E3 & 95 & 5 & LPO & 0.5 & 70 \\
E4 & 95 & 5 & BPO & 0.4 & 70 \\
E5 & 90 & 10 & T141 & 0.29 & 70 \\
E6 & 90 & 10 & LPO & 0.5 & 70 \\
\hline
\end{tabular}

to the performances obtained with the monofunctional initiators, using conversion and molar mass data for comparative purposes.

As shown in previous works (Castor et al., 2015, 2016), the concentration of $0.5 \mathrm{wt} \%$ (LPO) was taken as a reference for evaluation of active oxygen, which was similar when the concentration of bifunctional initiator (T141) was equal to $0.29 \mathrm{wt} \%$. Both concentrations lead to similar contents of active oxygen, making possible the comparison of polymer productivity obtained with these initiators.

To the best of our knowledge, there are no studies in the open literature regrading the application of the bifunctional initiator T141 in free radical copolymerization with vinyl chloride (mass, solution, emulsion and suspension).

\subsection{Characterization}

\subsubsection{Monomer conversion}

Raman spectra were obtained with a Raman spectrometer (RXN-1, Kaiser Optical System Inc.), using a near infrared laser diode ( $400 \mathrm{~mW}, 785 \mathrm{~nm}$ ) as excitation source. The Raman spectra were recorded in the range of $3200-200 \mathrm{~cm}^{-1}$. The microfluidic device was placed under the probe head of the spectrometer without physical contact. The distance between the optical lens and the reactor setup was approximately equal to $1.5 \mathrm{~cm}$, according to the experimental setup shown on Fig. 1. The acquisition and processing of spectral data were performed with the proprietary software provided by iC RamanTM 4.1 Mettler-Toledo. The probe head was focused on the microchannel with help of a y-z barrel micrometer.

Each spectrum was obtained after a total integration time of $45 \mathrm{~s}$ ( 3 scans of $15 \mathrm{~s}$ ) and the acquisition interval was equal to $120 \mathrm{~s}$, using a laser with nominal output power of $200 \mathrm{~mW}$. Because of the distance between the laser source and the droplets inside the microcapillary, it is estimated that the laser power can be reduced by up to $40 \%$, being influenced by several factors, including the microcapillary thickness and the aqueous phase.

\subsubsection{Droplets visualization}

The images of the droplets during the polymerization reactions were obtained with help of an Imager Intense CCD camera (LaVision, GmbH, Germany) with a maximum resolution of $1280 \times 1024$ pixels. The images were analyzed with the proprietary software Lavision 7.1. Details regarding the operation and applications provided by the software can be obtained from the user manual (LaVision, 2006). The camera was attached to a binocular microscope Olympus UIS2 (BXFM Olympus microscope system), equipped with an optical lens Olympus $\operatorname{LMPL}(65 \times)$ for better visualization of the internal content of the microcapillary.

\subsubsection{Average molar mass}

In order to obtain the samples for GPC analyzes, the polymer particles were taken from the silica tubings and then extracted the polymer materials for GPC analyses. Average molar masses were determined by Gel Permeation Chromatography (GPC) with a Viscotek VE 2001 equipment, using a Viscotek VE 3580 RI refractometer detector and a series of four Phenomenex columns with porosities of $5 \times 10^{2}, 10^{4}, 10^{5}$ and $10^{6} \AA$. THF was used as solvent at a flow rate of $1.0 \mathrm{ml} \mathrm{min}^{-1}$. Calibration was performed with polystyrene standards with average molar masses ranging from $3 \times 10^{3} \mathrm{~g} \mathrm{~mol}^{-1}$ to $3 \times 10^{6} \mathrm{~g} \mathrm{~mol}^{-1}$ and checked against PMMA standards with average molar masses ranging from $3 \times 10^{5}$ $\mathrm{g} \mathrm{mol}^{-1}$ to $3 \times 10^{6} \mathrm{~g} \mathrm{~mol}^{-1}$ (given the higher average molar masses of PMMA fractions) with good precision (indicating that corrections were not necessary). GPC analyzes of polymer samples were performed at $40^{\circ} \mathrm{C}$ and used to evaluate the average molar masses at the end of each reaction.

\section{Results and discussions}

\subsection{Raman monitoring procedure}

As described previously (Castor et al., 2015, 2016), the knowledge about the spectra of the materials that constitute the reaction medium comprises the first stage for the successful monitoring of the process. The methodology used in this work was the same one described in previous works (Castor et al., 2015, 2016). However, some considerations have to be highlighted for the present study.

By taking the peak related to the $\mathrm{C}=\mathrm{C}$ stretching in both MMA (Castor et al., 2015) and VCM (Castor et al., 2016), it becomes clear that these peaks do not overlap each other, as demonstrated in Fig. 2. The distance between the peaks is about $36 \mathrm{~cm}^{-1}$ as the resolution of Raman was equal to $1 \mathrm{~cm}^{-1}$. The greater the distance between the peaks, the higher the accuracy of the measurements due to the decrease of the influence of one particular peak over the other. In addition, it can be observed that the MMA spectrum presents peaks with lower intensities when compared to the VCM spectrum at similar conditions (power, focal distance, total integration time, temperature, etc). This difference could be explained by the higher polarity of methyl methacrylate, since tha Raman technique presents greater sensibility and responsiveness in genuinely nonpolar samples (Koenig, 1999).

The vibrational assignments for methyl methacrylate and vinyl chloride spectra are reported in Table 4. These vibrational bands were identified with the aid of various published works (Bodoc et al., 2012; Gulari et al., 1984; Edwards et al., 2006; Willis et al. 1969; Liebman et al., 1971; Maddans, 1977; Bowden et al., 1991). Particular attention must be observed to the peaks located at $1640 \mathrm{~cm}^{-1}$ and $1604 \mathrm{~cm}^{-1}$. These peaks can be associated with the $\mathrm{C}=\mathrm{C}$ stretching in both monomers, MMA and VCM, respectively. As studied reported in the literature (Castor et al., 2015, 2016), monitoring of these molecular vibrations indicates the monomer consumption during polymerization reactions.

Fig. 3 shows the evolution of the peak area of the carbon-carbon double bond throughout the reaction for both MMA and VCM monomers, respectively. The dispersion of data related to the $\mathrm{C}=\mathrm{C}$ vibration for MMA can be explained by the low values of the band area measurements at $1670-1770 \mathrm{~cm}^{-1}$, which increases its sensibility to the experimental noise during the signal acquisition.

In order to better understanding the phenomena involved in the Raman monitoring of this work, two facts should be highlighted to the reader:

- The organic solution MMA/VCM must provide Raman spectra for which the absorbances of the $\mathrm{C}=\mathrm{C}$ double bonds of each monomer do not overlap. In order to clarify this statement, Table 5 shows the wavelength of the $\mathrm{C}=\mathrm{C}$ bond of several monomers. 


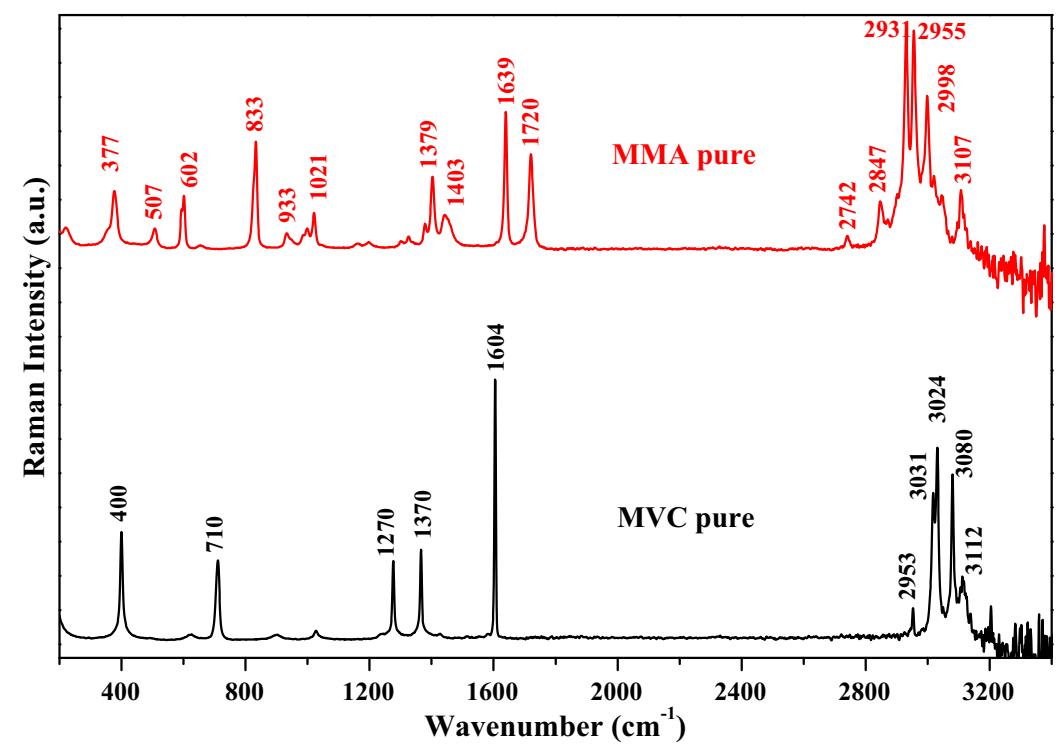

Fig. 2. Raman spectra of MMA and VCM at $20^{\circ} \mathrm{C} . \mathrm{t}_{a q}=50 \mathrm{~s}$ ( 5 scans of $10 \mathrm{~s}$ ).

Table 4

Raman bands observed in VCM and MMA spectra (Bodoc et al., 2012; Gulari et al., 1984; Edwards et al., 2006; Willis et al., 1969; Liebman et al., 1971; Maddans, 1977; Bowden et al., 1991).

\begin{tabular}{|c|c|c|}
\hline \multicolumn{2}{|c|}{ Peaks and Bands $\left(\mathrm{cm}^{-1}\right)$} & \multirow[t]{2}{*}{ Description of molecular vibrations } \\
\hline MMA & MVC & \\
\hline $350-380$ & - & $\delta(\mathrm{C}-\mathrm{C}-\mathrm{C}), \delta_{s}(\mathrm{CCO})_{i p}$ \\
\hline- & 400 & $\delta_{s}(\mathrm{C}=\mathrm{C}-\mathrm{Cl})$, aliphatic. $\mathrm{C}_{n}, \mathrm{n}=3 \ldots 12$ \\
\hline 507 & - & $\delta(\mathrm{C}-\mathrm{C}-\mathrm{O})$ \\
\hline 602 & - & $v(\mathrm{C}-\mathrm{COO}), v_{s}(\mathrm{C}-\mathrm{C}-\mathrm{O})$ isotactic \\
\hline- & $600-800$ & $\delta(\mathrm{C}-\mathrm{Cl})$ \\
\hline 832 & - & $v_{s}(\mathrm{C}-\mathrm{O}-\mathrm{C})$ syndiotactic \\
\hline $930-1000$ & - & $v(\mathrm{O}-\mathrm{C})$ \\
\hline 1021 & - & $v_{a s}(\mathrm{C}-\mathrm{C})$ \\
\hline- & 1270 & $\delta(=\mathrm{CH})$ aliphatic chains \\
\hline 1379 & 1370 & $\delta\left(\mathrm{CH}_{2}\right) \delta\left(\mathrm{CH}_{3}\right)$ asymmetric \\
\hline 1403 & - & $\delta\left(\mathrm{CH}_{2}\right)$ \\
\hline 1604 & 1640 & $v(\mathrm{C}=\mathrm{C})$ \\
\hline 1720 & - & $v(\mathrm{C}=0)$ \\
\hline 2847 & - & $v_{s}(\mathrm{C}-\mathrm{H})$ from $\mathrm{CH}_{2}$ or combinations of $v_{s}(\mathrm{O}-\mathrm{CH})$ \\
\hline 2931 & 2953 & $v_{s}\left(\mathrm{CH}_{2}\right), v_{s}\left(\mathrm{CH}_{2}\right)$ from $\mathrm{CH}_{3}$ or $\mathrm{O}-\mathrm{CH}_{3}, \mathrm{CH}_{2}$ \\
\hline $3000-3100$ & $3000-3100$ & $v(\mathrm{CH}=\mathrm{C}-\mathrm{H})$ \\
\hline
\end{tabular}

$\delta=$ deformation, $v=$ stretching, ip = plane, as = asymmetric, $\mathrm{s}=$ symmetric.

- Table 6 shows the reactivity ratios for various monomers, considering VCM as the first monomer. Interestingly, it is observed that the VCM reactivity is lower than for the other monomer in the most cases. In a solution mixture of MMA with VCM, the first one might be consumed almost completely before the end of the copolymerization, or even before the VCM reaction, which is explained by the high reactivity of MMA. Fig. 3 shows that MMA is completely depleted at very low VCM conversions.

Fig. 4 shows the evolution of the particular Raman bands when $5 \mathrm{wt} \%$ of MMA were added into the initial reaction mixture. This result indicates how those bands behave throughout the reaction, especially in the wavelength of the $\mathrm{C}-\mathrm{Cl}$ bond, related to the following bands $380-420 \mathrm{~cm}^{-1}, 590-670 \mathrm{~cm}^{-1}$ and $670-740 \mathrm{~cm}^{-1}$. Comparing this result with those observed for MMA and VCM homopolymerizations, it becomes clear that the bands at 380$420 \mathrm{~cm}^{-1}$ and $590-670 \mathrm{~cm}^{-1}$ present similar behavior during the MMA/VCM copolymerization (see Table 4).

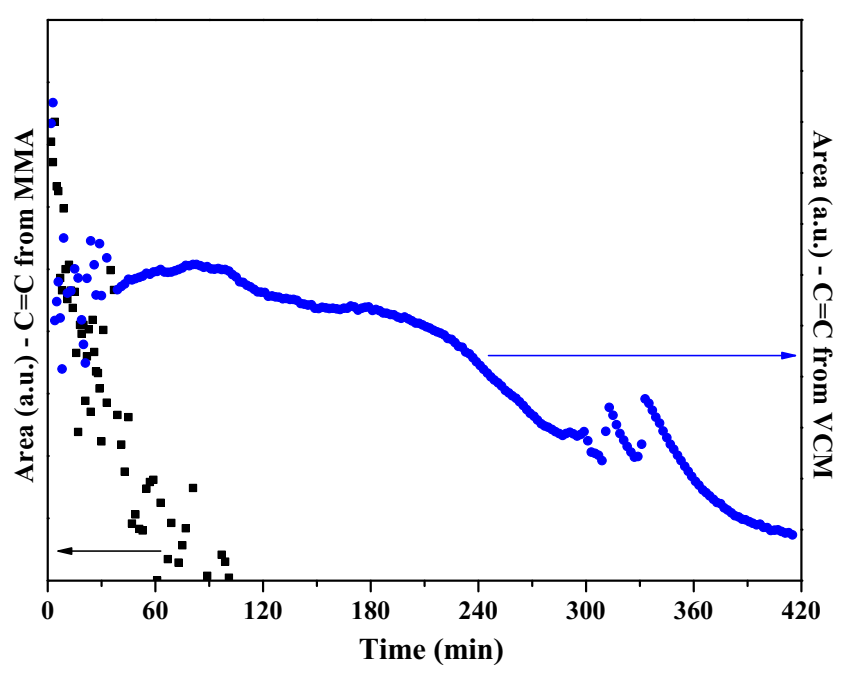

Fig. 3. Evolution of the peak areas of the carbon-carbon double bond during the experiment E2 for both monomers, MMA and VCM.

Table 5

Raman band of the carbon-carbon bond for various monomers (McCreery, 2000; Koenig, 1999; Joyner and Glockler, 1952).

\begin{tabular}{lc}
\hline Monomer & $\begin{array}{c}\text { Wavelength of the } \\
\mathrm{C}=\mathrm{C} \text { bond }\left(\mathrm{cm}^{-1}\right)\end{array}$ \\
\hline Vinyl chloride & 1604 \\
Vinylidene chloride & 1607 \\
Acrylonitrile & 1610 \\
Styrene & 1631 \\
Methyl acrylate & 1635 \\
2-ethylhexyl acrylate & 1637 \\
Butadiene & 1639 \\
Methyl methacrylate & 1640 \\
Vinyl acetate & 1648 \\
$\alpha$-Methylene- $\gamma$-butyrolactone & 1660 \\
\hline
\end{tabular}

In relation to the Raman band at $670-740 \mathrm{~cm}^{-1}$, which was used as a reference peak for monitoring the VCM polymerization (Castor et al., 2016), it is important to observe that it does not overlap on any other MMA Raman band. However, as observed in Fig. 4, 
Table 6

Reactivity ratios, assuming that the vinyl chloride is the first monomer $\left(r_{1}\right)$ (Brandrup et al., 1999; Burgess, 2005; Nass and Leonard, 1998).

\begin{tabular}{lcc}
\hline Monomer & \multicolumn{2}{c}{ Reactivity ratio } \\
\cline { 2 - 3 } & $r_{1}$ & $r_{2}$ \\
\hline Vinylidene chloride & 0.3 & 3.2 \\
Vinyl acetate & 1.8 & 0.24 \\
2-ethylhexyl acrylate & 0.16 & 4.15 \\
Methyl acrylate & 0.093 & 4.4 \\
Acrylonitrile & 0.04 & 2.7 \\
Maleic anhydride $\left(75^{\circ} \mathrm{C}\right)$ & 0.3 & 0.008 \\
Butadiene $\left(50^{\circ} \mathrm{C}\right)$ & 0.04 & 8.8 \\
Styrene & 0.02 & 17 \\
Methyl methacrylate $\left(68{ }^{\circ} \mathrm{C}\right)$ & 0.1 & 10 \\
\hline
\end{tabular}

All measurements were taken at $60\left({ }^{\circ} \mathrm{C}\right)$, except where noted.

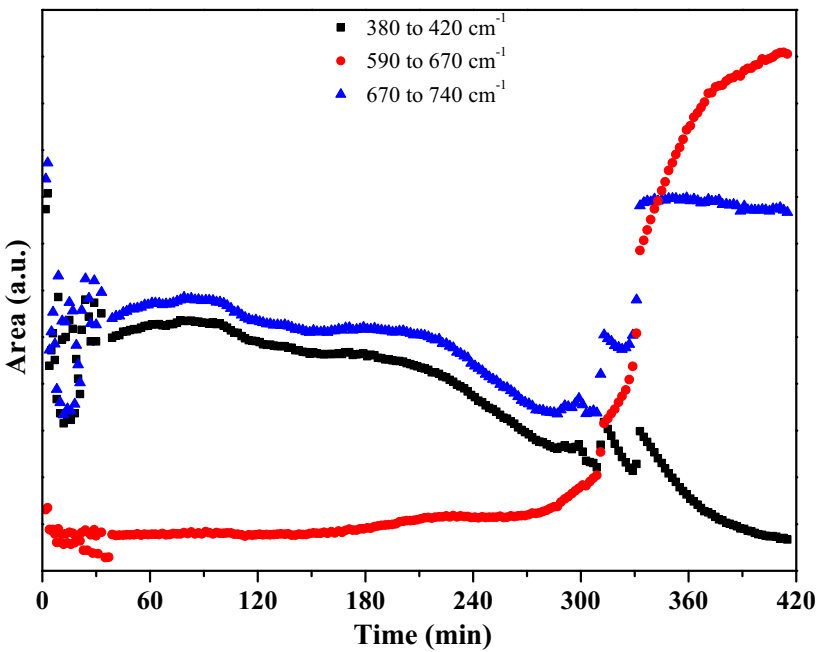

Fig. 4. Evolution of the peak areas of the chloride-carbon bond during the experiment E2.

the band $\left(670-740 \mathrm{~cm}^{-1}\right)$ decreases its intensity until the beginning of the gel effect, differently the PVC kinetics (Castor et al., 2016), where such Raman band was subject only to smooth changes. Then, after the onset of the gel effect, it is observed that the band at $670-740 \mathrm{~cm}^{-1}$ remains constant until the end of the copolymerization. Here, two possible scenarios cab be provided: (1) The $\mathrm{C}-\mathrm{Cl}$ bond may have been consumed during the copolymerization. (2) The change in the internal composition of the droplet causes changes in the optical properties of the medium during the reaction so that such effect is captured by the Raman technique. The second explanation is more likely because these optical effects were shown to occur with the help of images provided by the CCD camera.

In conclusion, by using the Raman band at $670-740 \mathrm{~cm}^{-1}$ as an internal reference for the normalization, one can obtain the conversion data of the copolymerization, as shown in Fig. 5. In addition, in order to obtain the copolymer composition, the evolution of the $\mathrm{C}=\mathrm{C}$ band is shown for MMA. As discussed earlier, MMA is completely consumed in the first 90 min of the reaction. This can be explained by the reactivity ratios (see Table 6 ). With regard to the VCM conversion, the same internal reference used previously (Castor et al., 2016) was used here. It is possible to affirm that, after 100 min of the reaction (E2), the copolymer has 5\% of PMMA and $2 \%$ of PVC, approximately. At the end of the Experiment E2, a copolymer composition with 5\% of PMMA and 90\% of PVC can be obtained. It is important to note that the final polymer mixture is formed essentially as a blend of PMMA and PVC, as the data from Raman spectroscopy suggest. In order to calculate the copolymer

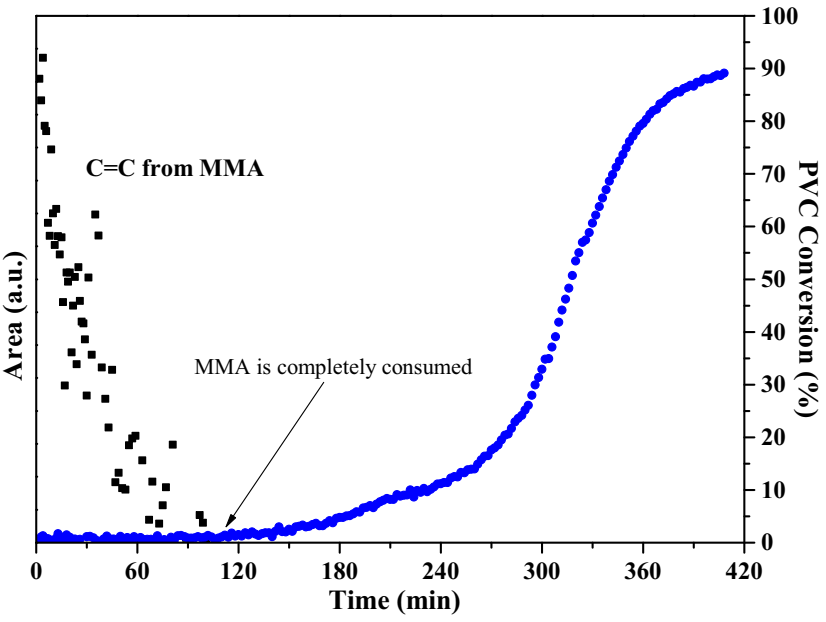

Fig. 5. Evolution of the peak areas of the $\mathrm{C}=\mathrm{C}$ bond from MMA and PVC conversion according to the Experiment E2.

composition in all experiments, the Raman band at 670$740 \mathrm{~cm}^{-1}$ was used as a internal reference, as carried out in the previous work with pure PVC (Castor et al., 2016).

\subsection{Suspension polymerization reactions}

\subsubsection{Polymerization kinetics}

From the Fig. 5 one can observe that the copolymerization kinetics is slower if compared to the homopolymerization reactions of MMA (Castor et al., 2015) and VCM (Castor et al., 2016), which can be explained by the reactivity ratios, according to the data shown in Table 6. Furthermore, this copolymerization kinetics is dominated by slower rates of propagation. In order to better understand this statement, Fig. 6 shows kinetic data for the MMA and VCM homopolymerizations and for the copolymerization, Experiment E2, all performed as similar reaction conditions.

The strong influence of only $5 \mathrm{wt} \%$ of MMA can be observed in the copolymerization with VCM. The strong modification of the copolymer composition throughout the reaction indicate that the copolymer is substantially non-uniform, probably forming a blend of polymer of different compositions. This non-uniformity might be solved by adding the MMA in semi-batch mode, which is beyond the scope of present work.

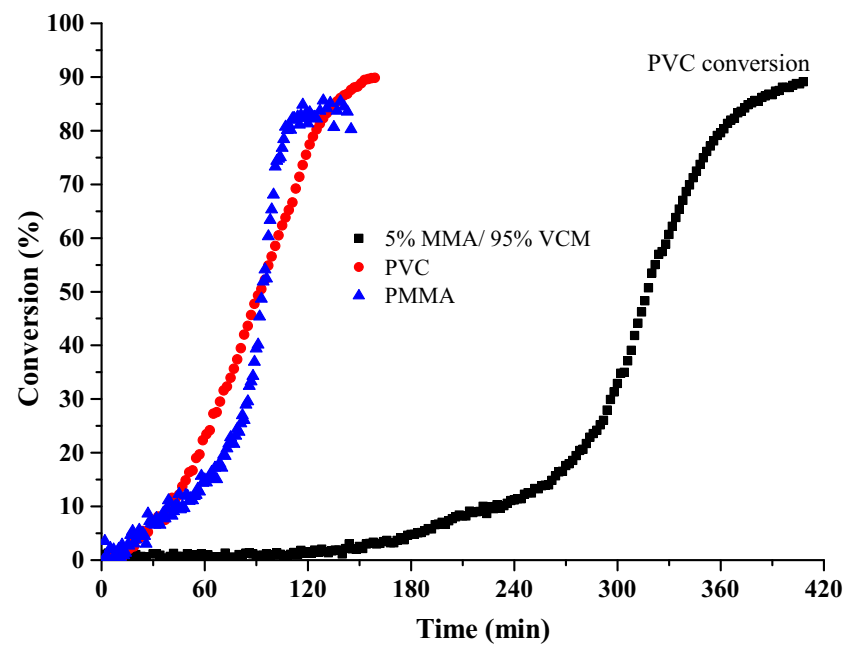

Fig. 6. Conversion data for MMA and VCM homopolymerizations and MMA/VCM copolymerization. 
Table 7

Chain transfer values $\left(C_{m}\right)$ for both VCM and MMA (Brandrup et al., 1999; Starnes et al., 1998).

\begin{tabular}{lcc}
\hline \multirow{2}{*}{ Monomer } & \multicolumn{2}{c}{ Temperature } \\
\cline { 2 - 3 } & \multicolumn{1}{c}{$60{ }^{\circ} \mathrm{C}$} & $70^{\circ} \mathrm{C}$ \\
\hline Vinyl chloride & $1.08-1.28\left(\times 10^{-3}\right)$ & $2.2 \times 10^{-3}$ \\
Methyl methacrylate & $0.07-0.18\left(\times 10^{-4}\right)$ & $0.18-1.7\left(\times 10^{-4}\right)$ \\
\hline
\end{tabular}

In order to better understand how each monomer affects the chain transfer during the course of the copolymerization, Table 7 shows the constant values for chain transfer as function of the temperature as obtained from the literature (Brandrup et al., 1999; Starnes et al., 1998). These values show that the molar mass of the MMA/VCM copolymer is probably controlled by chain transfer to the VCM. As conversion increases, the MMA is rapidly consumed and the relative amount of propagating radicals increase, as a result, the reaction accelerates. This acceleration is similar to the gel effect in a free-radical polymerization of methyl methacrylate.

Fig. 7(a) shows the effect of the MMA concentration on the vinyl chloride suspension copolymerization kinetics by using $0.29 \mathrm{wt} \%$ of the bifunctional initiator $\mathrm{T} 141$, at $70^{\circ} \mathrm{C}$. Once again, it is observed the retardant effect of the MMA on the copolymerization with VCM. The increase from 5 to $10 \mathrm{wt} \%$ of MMA extended the reaction in about $120 \mathrm{~min}$. The same result is obtained when a monofunctional initiator was used, as shown in Fig. 7(b), considering the same active oxygen concentration. This result is similar to others published in the literature (Bichuch et al., 2003); however, using macroreactor volumes ranging from 3 to $5 \mathrm{l}$ at low temperatures $\left(60^{\circ} \mathrm{C}\right.$ ) with a mixture of monofuntional initiators (PD and LPO). As a conclusion, the chemical nature of the MMA is determinant to the kinetics of the copolymerization with VCM, regardless of the type of initiator used.

Table 8 shows the average molar mass and dispersity results of homopolymer PVC (Castor et al., 2016) by using the bifunctiona initator T141. Basically, it is observed that the results are almost the same, which is due to the chain transfer to the VCM. By using the monofunctional initiators LPO and BPO, larger differences in the $\mathrm{M}_{w}$ and $\mathrm{M}_{n}$ values can be observed when the MMA concentration is increased in the initial mixture (see Table 9), but still similar to the other results presented above.

It is likely that the small differences in the molar mass of the copolymers can be explained in terms of the large difference between the chain propagation constant of both monomers and the controlling effect exerted by chain transfer to VCM. In addition, the cross termination is usually favored in free-radical copolymer-
Table 8

Average molar masses results at $70{ }^{\circ} \mathrm{C}$ with the bifunctional initiator T141.

\begin{tabular}{lccc}
\hline Composition & $\begin{array}{c}\bar{M}_{w} \\
(\mathrm{~kg} / \mathrm{mol})\end{array}$ & $\begin{array}{c}\bar{M}_{n} \\
(\mathrm{~kg} / \mathrm{mol})\end{array}$ & $\begin{array}{c}\text { Đ } \\
(-)\end{array}$ \\
\hline Pure PVC & 93,000 & 46,000 & 2.02 \\
5 wt\% MMA & 89,000 & 43,000 & 2.07 \\
10 wt\% MMA & 88,000 & 42,000 & 2.09 \\
\hline
\end{tabular}

Table 9

Average molar masses results at $70{ }^{\circ} \mathrm{C}$ with the monofunctional initiators LPO and BPO.

\begin{tabular}{lccccc}
\hline Composition & Initiator & $\begin{array}{c}\text { Concentration } \\
(\text { wt\% })\end{array}$ & $\begin{array}{c}\bar{M}_{w} \\
(\mathrm{~kg} / \mathrm{mol})\end{array}$ & $\begin{array}{c}\bar{M}_{n} \\
(\mathrm{~kg} / \mathrm{mol})\end{array}$ & $\begin{array}{c}Ð \\
(-)\end{array}$ \\
\hline Pure PVC & LPO & 0.5 & 98,000 & 46,000 & 2.13 \\
5 wt\% & LPO & 0.5 & 90,000 & 45,000 & 2.00 \\
10 wt\% MMA & LPO & 0.5 & 81,000 & 42,000 & 1.93 \\
Pure PVC & BPO & 0.4 & 93,000 & 51,000 & 1.82 \\
5 wt\% MMA & BPO & 0.4 & 86,000 & 43,000 & 2.00 \\
\hline
\end{tabular}

izations. But the dominant effect is exerted by the chain transfer to the VCM.

As concluded earlier, the copolymerization kinetics of the MMA/VCM is independent of the type of initiator used. In order to evaluate the effect of the different initiators in respect to the their functionality, Fig. 8 shows the conversion data obtained with the initiators LPO, BPO and T141 for different compositions of MMA. As expected, the same qualitative behavior can be observed for the copolymerization of VCM regardless of the initial concentration of the MMA in the reaction medium.

Table 10 shows the average molar mass and dispersity results when different initiators were used in the MMA/VCM suspension copolymerization. The bifunctional initiator seems to cause a small increase of the average molar mass for constant copolymer composition. Furthermore, dispersity data obtained with the T141 were lower than others for the same initial composition of MMA (5\% and $10 \%$ ). This is probably related to the bifunctional character of T141, as it is known that bifunctional initiators can lead to decrease of the dispersity index in polymerizations controlled by chain transfer to monomer (Castor et al., 2016).

The temperature effect on copolymerization kinetics with $5 \mathrm{wt} \%$ MMA/95 wt\% VCM is shown in Fig. 9. The increase of $5{ }^{\circ} \mathrm{C}$ on the reaction temperature it caused a significant effect on the kinetics with the bifuncional initiator T141, decreasing the reaction time in about $160 \mathrm{~min}$. Among the other variations (type of initiator

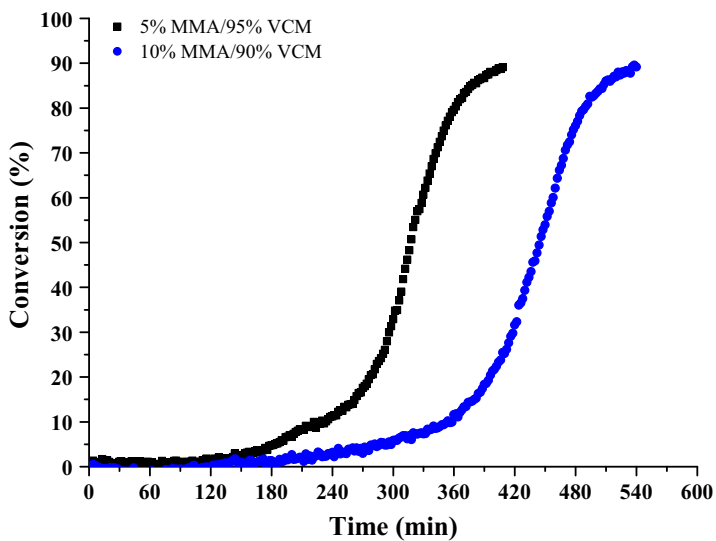

(a) $[\mathrm{I}]_{T 141}=0.29 \mathrm{wt} \%$

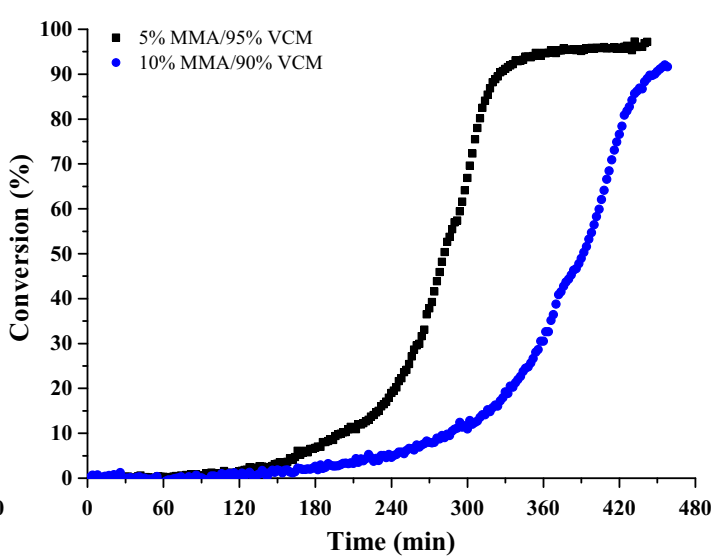

(b) $[\mathrm{I}]_{L P O}=0.5 \mathrm{wt} \%$

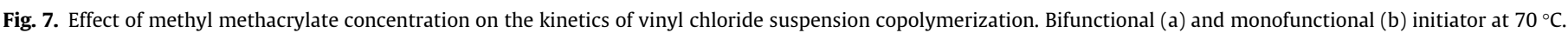




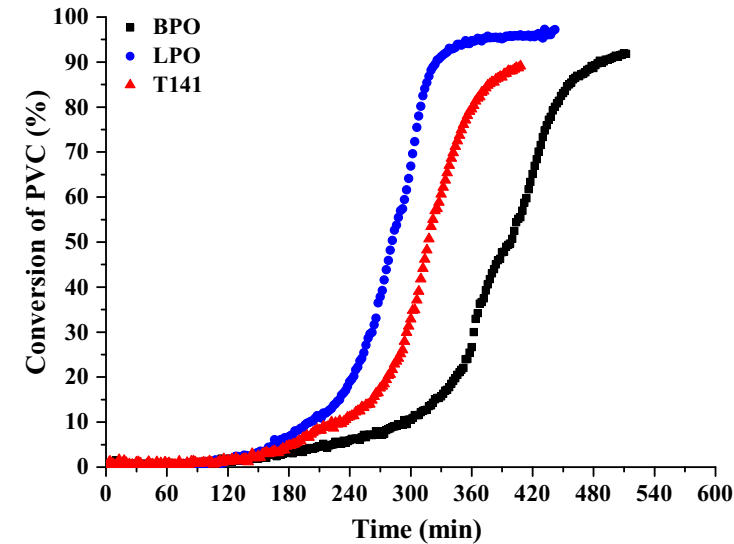

(a) $5 \mathrm{wt} \% \mathrm{MMA} / 95 \mathrm{wt} \% \mathrm{MVC}$

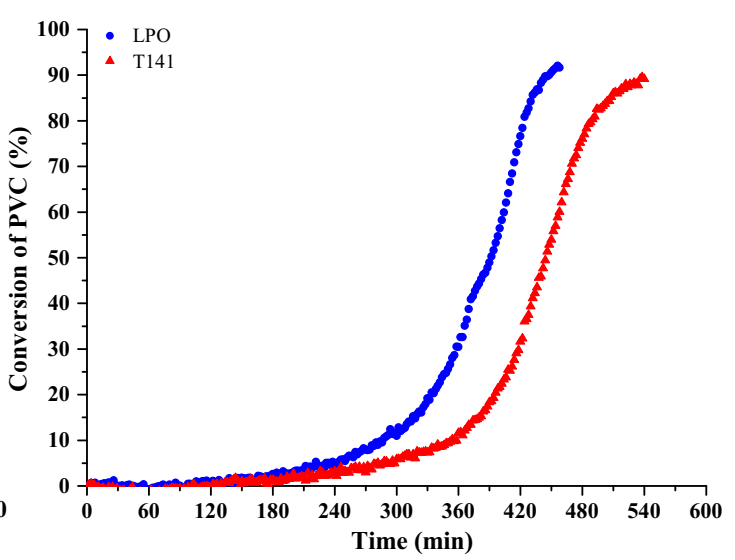

(b) $10 \mathrm{wt} \% \mathrm{MMA} / 90 \mathrm{wt} \% \mathrm{MVC}$

Fig. 8. Effect of the type of initiator on the kinetics of the MMA/VCM suspension copolymerization at $70^{\circ} \mathrm{C}$.

Table 10

$M_{w}, M_{n}$ and $Đ$ results in terms of the type of initiator at $70{ }^{\circ} \mathrm{C}$

\begin{tabular}{lcccc}
\hline $\begin{array}{l}\text { Composition } \\
\text { of the copolymer }\end{array}$ & Initiator & $\begin{array}{c}\bar{M}_{w} \\
(\mathrm{~kg} / \mathrm{mol})\end{array}$ & $\begin{array}{c}\bar{M}_{n} \\
(\mathrm{~kg} / \mathrm{mol})\end{array}$ & $\begin{array}{c}\text { Đ } \\
(-)\end{array}$ \\
\hline 5 wt\% PMMA & LPO & 90,000 & 45,000 & 2.00 \\
5 wt\% PMMA & BPO & 86,000 & 43,000 & 2.00 \\
5 wt\% PMMA & T141 & 89,000 & 43,000 & 2.07 \\
10 wt\% PMMA & LPO & 81,000 & 42,000 & 1.93 \\
10 wt\% PMMA & T141 & 88,000 & 42,000 & 2.09 \\
\hline
\end{tabular}

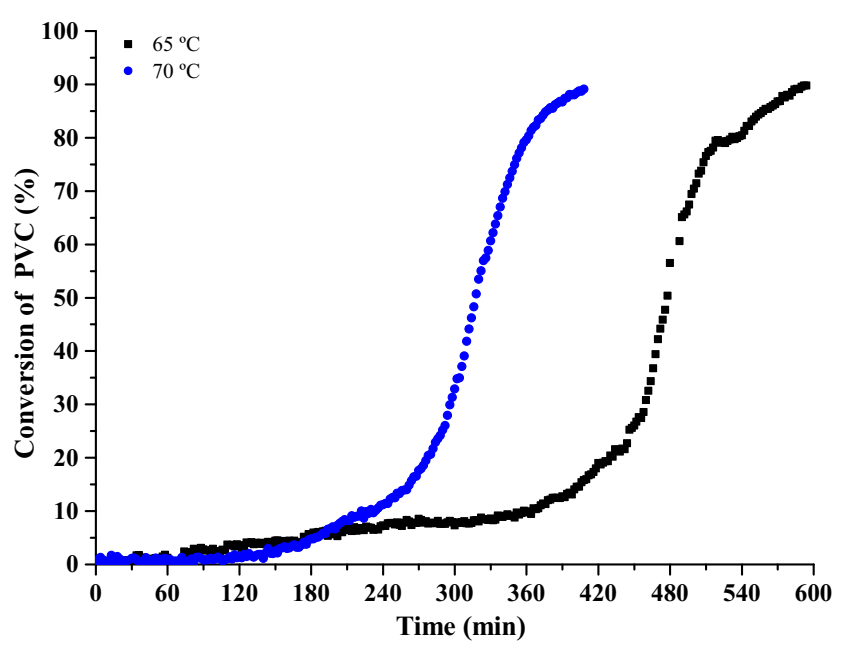

Fig. 9. Temperature effect on the MMA/VCM copolymerization in microreactors.

and initial composition of the reacting mixture) carried out in the MMA/VCM copolymerization, the temperature increase was the most significant one. Furthermore, the possible production of MMA/VCM copolymers should be conducted at higher temperatures.

\subsection{Monitoring of droplets/particles volume}

As reactions were conducted with the droplets dispersed in the aqueous phase inside the microcapillary in quiescent state, the effects of agitation were removed. That means that break-up and coalescence phenomena were not present. In order to understand the behavior of the reacting droplets (MMA/VCM) during heating of the microreactor, photographs were taken and analyzed according to the methodology previously described.

Fig. 10 shows the evolution of the droplets as function of the temperature, obtained by the CCD camera in the experiment E2. Due to the presence of MMA, the increase of the refraction index can be noted, as reported in the literature (Castor et al., 2016), being possible to visualize the droplets from 20 to $60^{\circ} \mathrm{C}$ (Fig. 10 (e)). The refraction index of the mixture increases with the MMA concentration inside the droplets. In addition, the droplets with MMA and VCM increase with temperature because of the decreasing densities as observed in Fig. 11.

It is well known that the production of free-radicals through initiator decomposition is accelerated as the temperature increases. During the heating phase, some small property changes might start to occur inside the droplets. It is shown that the droplets volume decrease start to decrease when the microreactor reaches $69^{\circ} \mathrm{C}$ (Fig. 11(a)). It can be considering, from these results, that the polymerization reaction started at this point. This particular behavior on the droplets was observed in all experiments carried out in this work.

It is observed in Fig. 11 similar profiles of the variations of droplets volume in others homopolymerizations performed in microreactors (Castor et al., 2015, 2016). However, due to the presence of the MMA, the droplets undergo a greater decrease of the volume after all MMA is consumed, after two hours, approximately for experiment (E4). This result supports our conclusion that MMA acts as a retarding agent in the copolymerization with the VCM. It is interesting to note the marked increase in volume in a wide range of conversion during the copolymerizations, which can not be explained only by density variations in the reaction medium.

Fig. 12 shows a set of photos taken during the course of the copolymerization with $5 \mathrm{wt} \% \mathrm{MMA} / 95 \mathrm{wt} \% \mathrm{VCM}$ and using a monofuntional initiator BPO. Unlike the homopolymers PMMA and PVC obtained in microreactors (Castor et al., 2015, 2016), the MMA/VCM suspension copolymerization presents a very particular characteristics related to morphological evolution of the droplets. At the beginning of the process, one can observe the formation of a film around the droplets, which is supposed to be formed by a graft copolymer of poly(methyl methacrylate)/poly(vinyl alcohol). The formation of this membrane already been proposed in the literature of suspension polymerization processes (Burgess, 2005). This phenomenon was observed in all polymerization reactions in microreactor conducted in this work.

At a certain instant of time the formation of a small core in the middle of the droplets can be observed. The formation of this core 
(a) $20{ }^{\circ} \mathrm{C}$

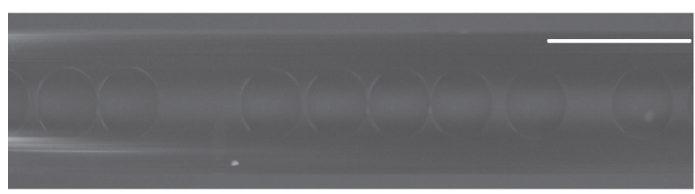

(c) $40{ }^{\circ} \mathrm{C}$

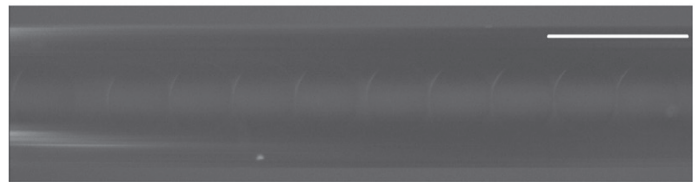

(e) $60{ }^{\circ} \mathrm{C}$

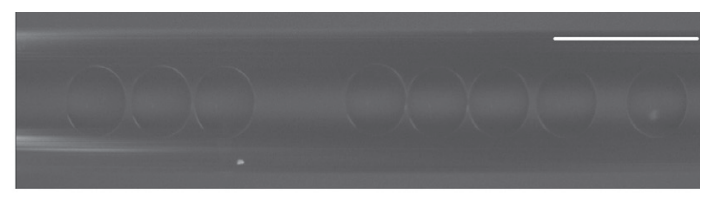

(b) $30{ }^{\circ} \mathrm{C}$

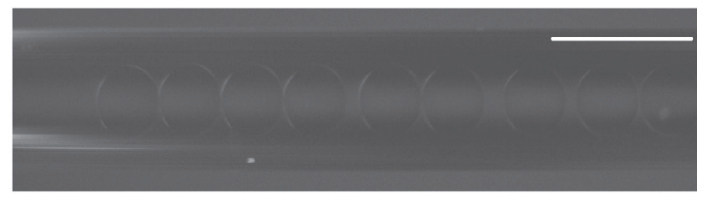

(d) $50{ }^{\circ} \mathrm{C}$

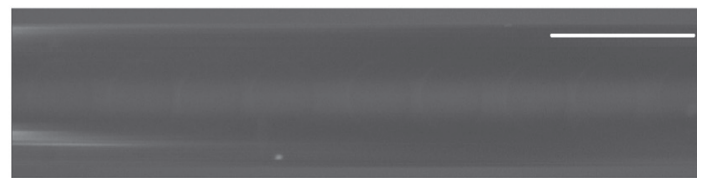

(f) $69{ }^{\circ} \mathrm{C}$

Fig. 10. Evolution of droplets during the MMA/VCM copolymerization, according to experiment E4. Bar length $=530 \mu \mathrm{m}$.

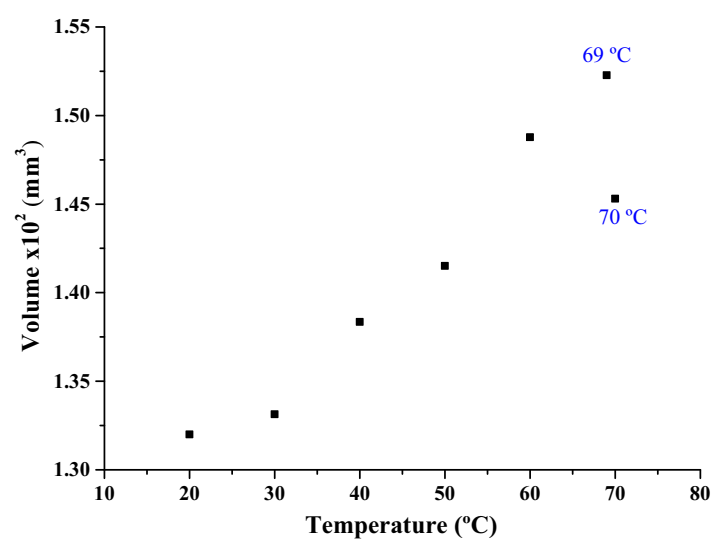

(a) Volume $\left(\mathrm{mm}^{3}\right) \times$ Temperature $\left({ }^{\circ} \mathrm{C}\right)$

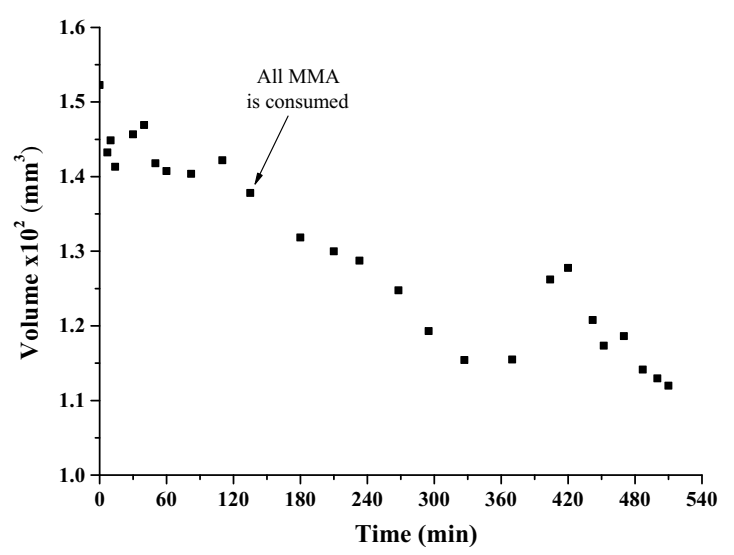

(b) Volume $\left(\mathrm{mm}^{3}\right) \times$ Time $(\mathrm{min})$

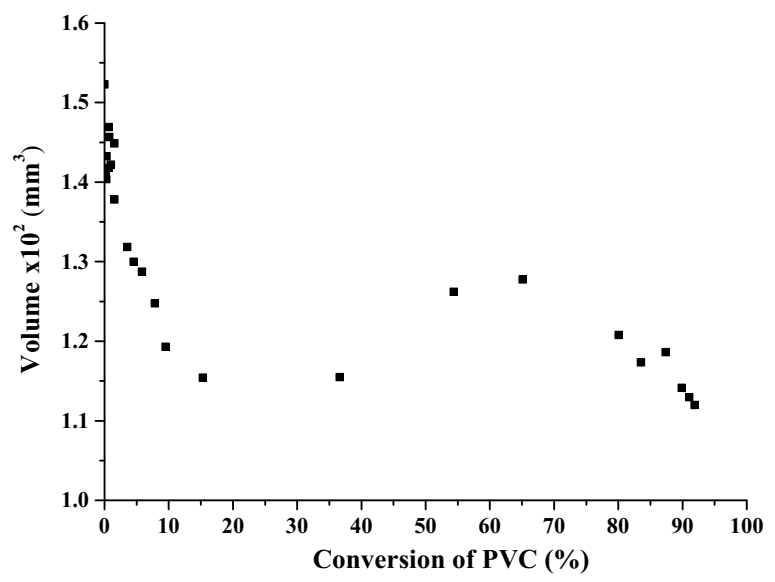

(c) Volume $\left(\mathrm{mm}^{3}\right) \times$ Conversion (\%)

Fig. 11. Effect of temperature on the evolution of the droplets in the suspension copolymerization of MMA/VCM in microreactor. Experiment E4. 


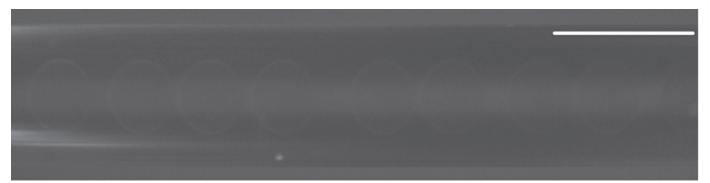

(a) $\mathrm{X}_{p m m a} \approx 3 \%$ and $\mathrm{X}_{p v c}=0.0 \%$

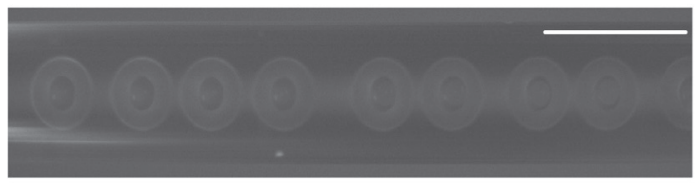

(c) $\mathrm{X}_{p m m a} \approx 80 \%$ and $\mathrm{X}_{p v c}=1.2 \%$

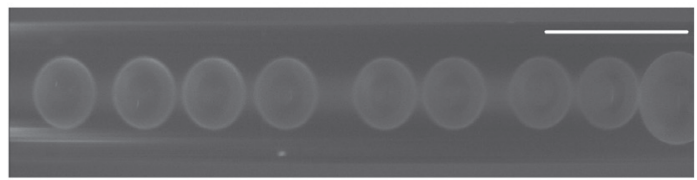

(e) $\mathrm{X}_{p m m a}=100 \%$ and $\mathrm{X}_{p v c}=4.0 \%$

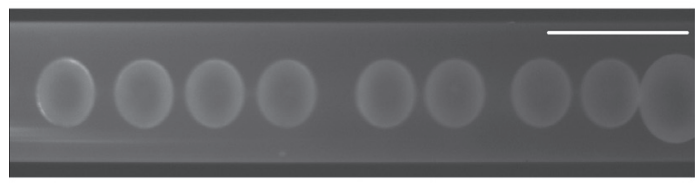

(g) $\mathrm{X}_{p m m a}=100 \%$ and $\mathrm{X}_{p v c}=37 \%$

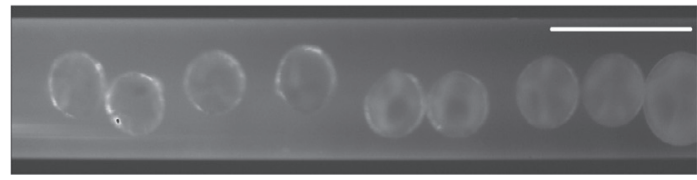

(i) $\mathrm{X}_{p m m a}=100 \%$ and $\mathrm{X}_{p v c}=80 \%$

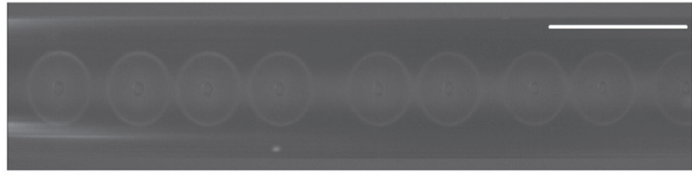

(b) $\mathrm{X}_{p m m a} \approx 15 \%$ and $\mathrm{X}_{p v c}=0.05 \%$

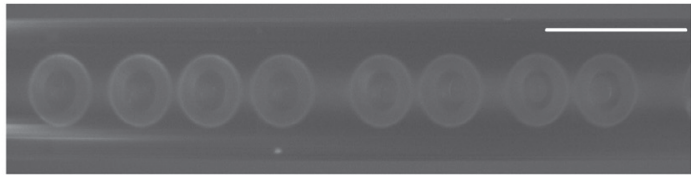

(d) $\mathrm{X}_{p m m a} \approx 90 \%$ and $\mathrm{X}_{p v c}=3.1 \%$

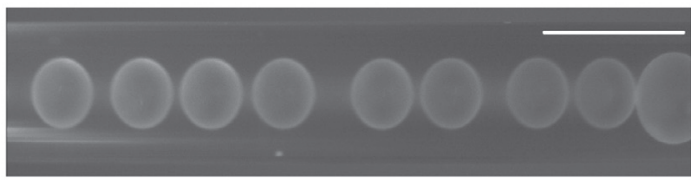

(f) $\mathrm{X}_{p m m a}=100 \%$ and $\mathrm{X}_{p v c}=8.0 \%$

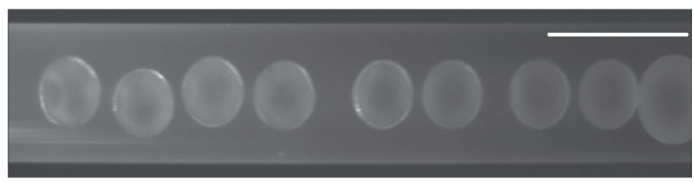

(h) $\mathrm{X}_{p m m a}=100 \%$ and $\mathrm{X}_{p v c}=55 \%$

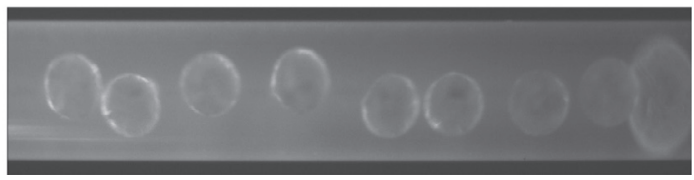

(j) $\mathrm{X}_{p m m a}=100 \%$ and $\mathrm{X}_{p v c}=90 \%$

Fig. 12. Evolution of the droplets/particles during the MMA/VCM copolymerization. Experiment E4. Bar length $=530 \mu \mathrm{m}$.

is surprising and has never been described before in any suspension polymerization systems. The formation of this core may be related to the precipitation of the initially formed MMA-rich polymer chains, as PMMA and PVC are not compatible (Burgess, 2005). As consequence, the liquid that makes up the core may be formed by the vinyl chloride. This assumption is based on the evolution of a single isolated droplet, as presented in Fig. 13. While PMMA concentration increases, the volume of the core also increases, which can be easily seen in Fig. 13. This phenomena is also observed in Fig. 11(b) where the volume of the original droplet decreased $9 \%$ after consuming all MMA monomer from the reacting medium. This assumption is related to the increased opacity around the nucleus. The interpretation adopted here is consistent with the fact that the PMMA is not soluble in VCM. After consuming all MMA, there has been a change of coloration within the nucleus probably caused by precipitation of the PVC chains (see Fig. 12(d)). Then, the entire particle becomes turbid, indicating a generalized formation of PVC. These phenomena identified in Experiment E4 also occurred in all copolymerizations that contained an initial solution of $5 \mathrm{wt} \% \mathrm{MMA} / 95 \mathrm{wt} \% \mathrm{MVC}$, regardless of the type of initiator and its concentration.

In respect to the $10 \mathrm{wt} \% \mathrm{MMA} / 10 \mathrm{wt} \% \mathrm{MVC}$ copolymerization, Fig. 14 shows a set of photos from the microreactor during the heating of the system. The visualization of the droplets was similar to that one described earlier, with similar increases in volume, as shown in Fig. 15.
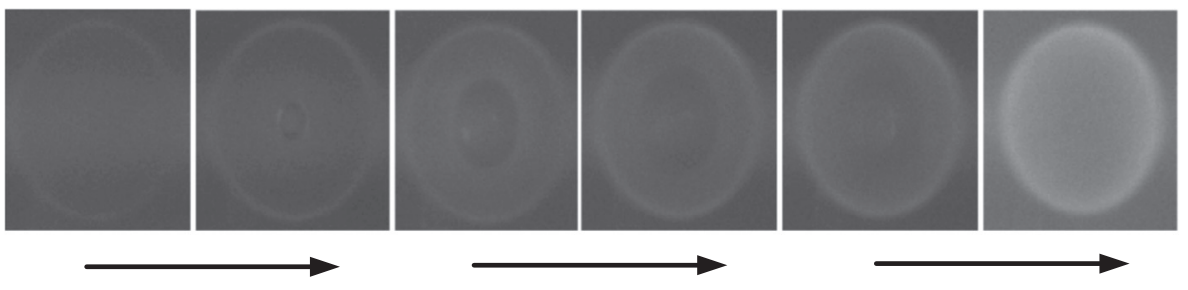

Fig. 13. Evolution of a single droplet in the Evolução 5 wt\% MMA/95 wt\% VCM copolymerization. Experiment E4. 
(a) $22{ }^{\circ} \mathrm{C}$

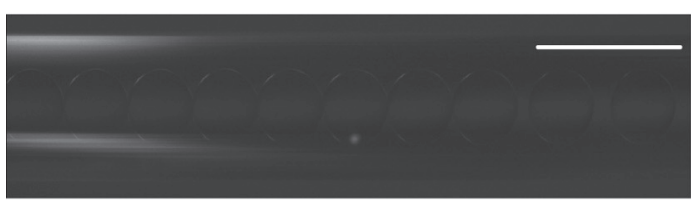

(c) $45^{\circ} \mathrm{C}$

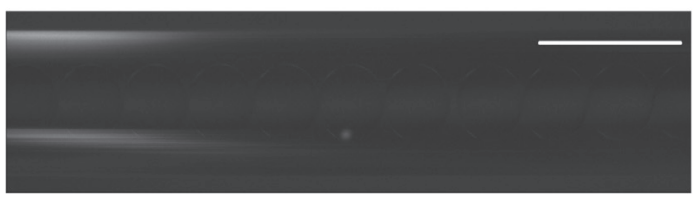

(e) $60{ }^{\circ} \mathrm{C}$

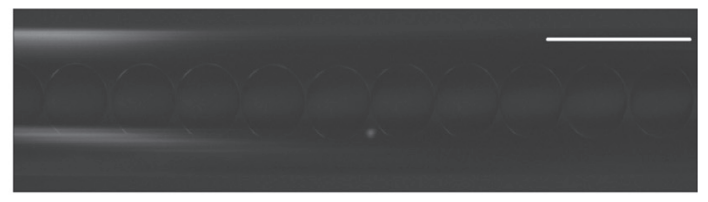

(b) $30{ }^{\circ} \mathrm{C}$

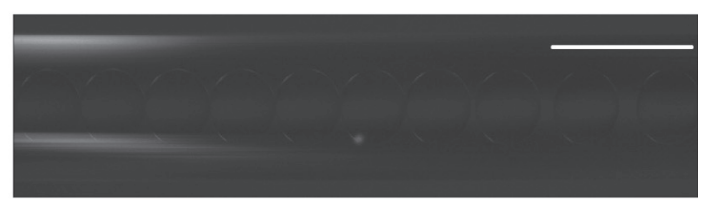

(d) $50{ }^{\circ} \mathrm{C}$

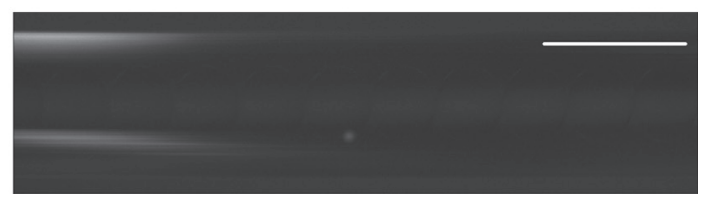

(f) $65^{\circ} \mathrm{C}$

Fig. 14. Evolution of the droplets/particles during the MMA/VCM copolymerization. Experiment E6. Bar length $=530 \mu \mathrm{m}$.

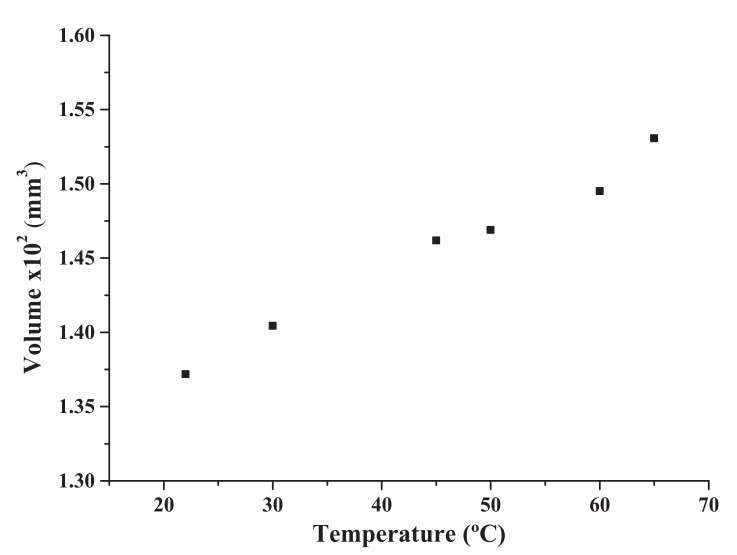

(a) Volume $\left(\mathrm{mm}^{3}\right) \times$ Temperature $\left({ }^{\circ} \mathrm{C}\right)$

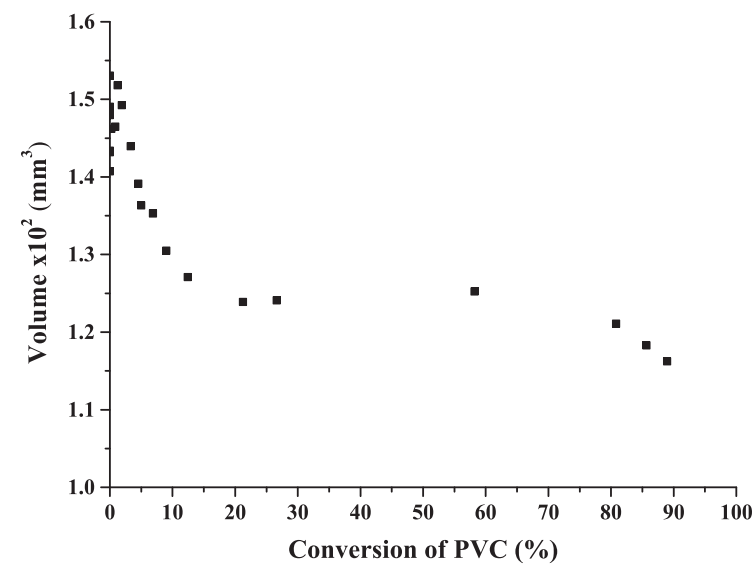

(c) Volume $\left(\mathrm{mm}^{3}\right) \times$ Conversion $(\%)$

Fig. 15. Effect of the temperature on the evolution of the droplets in the suspension copolymerization of MMA/VCM in microreactor. Experiment E6. 


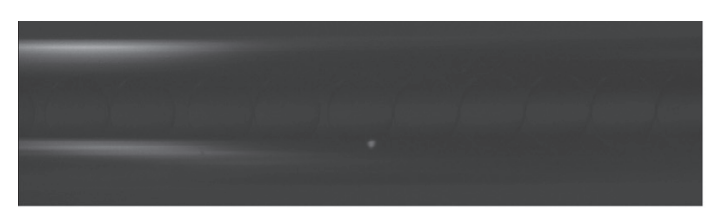

(a) $\mathrm{X}_{p m m a} \approx 17 \%$ and $\mathrm{X}_{p v c}=0.0 \%$

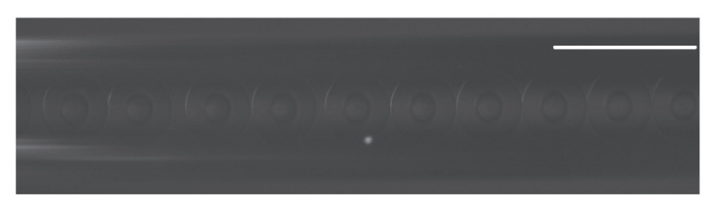

(c) $\mathrm{X}_{p m m a} \approx 36 \%$ and $\mathrm{X}_{p v c}=0.05 \%$

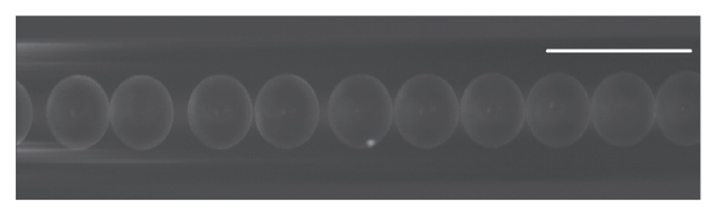

(e) $\mathrm{X}_{p m m a}=100 \%$ and $\mathrm{X}_{p v c}=7.0 \%$

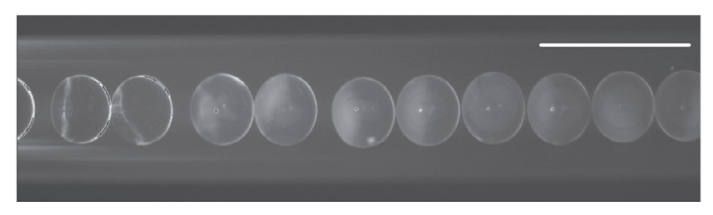

(g) $\mathrm{X}_{p m m a}=100 \%$ and $\mathrm{X}_{p v c}=68 \%$

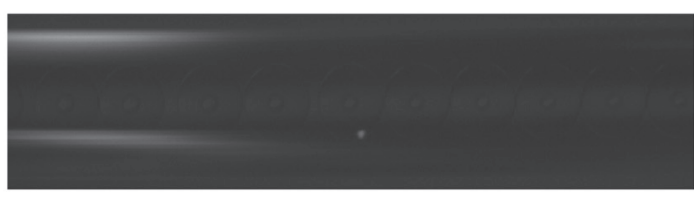

(b) $\mathrm{X}_{p m m a} \approx \%$ and $\mathrm{X}_{p v c}=0.0 \%$

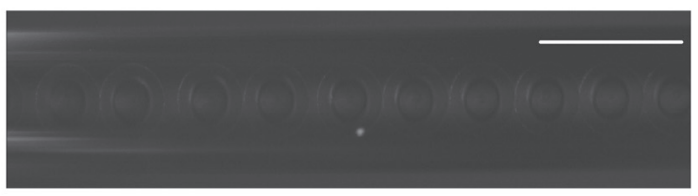

(d) $\mathrm{X}_{p m m a} \approx 60 \%$ and $\mathrm{X}_{p v c}=1.2 \%$

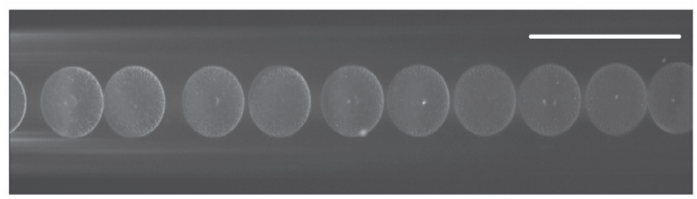

(f) $\mathrm{X}_{p m m a}=100 \%$ and $\mathrm{X}_{p v c}=25.0 \%$

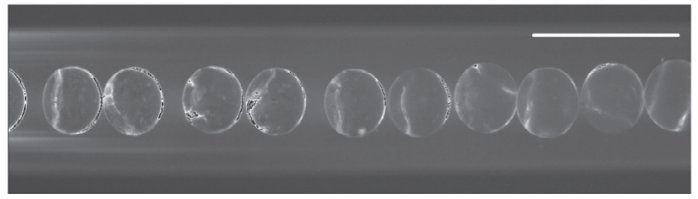

(h) $\mathrm{X}_{p m m a}=100 \%$ and $\mathrm{X}_{p v c}=89.7 \%$

Fig. 16. Evolution of droplets/particles during the MMA/VCM copolymerization. Experiment E6. Bar length $=530 \mu \mathrm{m}$.

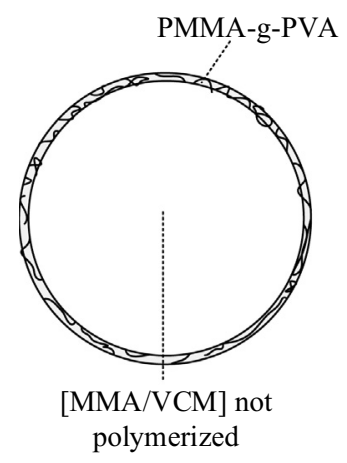

After some $t$ minutes of reaction

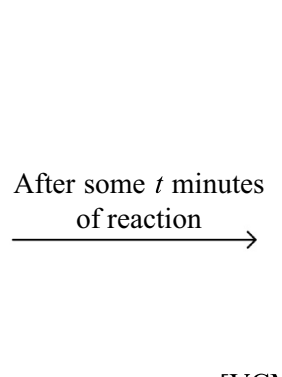

$[\mathrm{VCM}]$ not polymerized

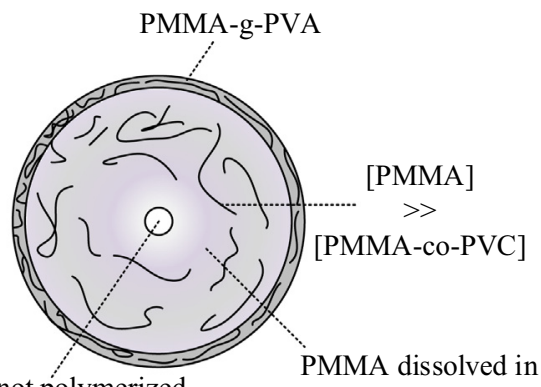

MMA/VCM

After reacting all MMA

$\downarrow$

PMMA-g-PVA

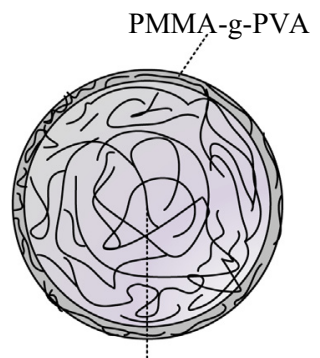

$[\mathrm{PMMA}-$ co-PVC $]<[\mathrm{PVC}]<[\mathrm{VCM}]$

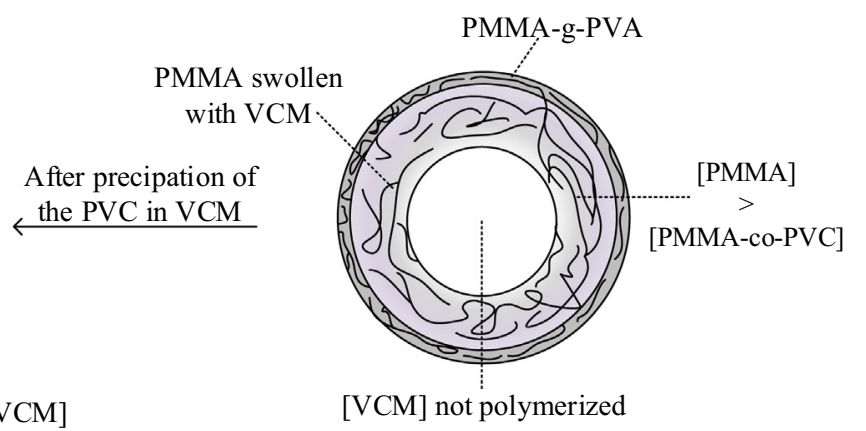

Fig. 17. Representative model proposed in the copolymerization of droplets in quiescent state of MMA with VCM. 
Regarding the behavior of the droplets volume in the vinyl chloride copolymerization with $10 \mathrm{wt} \% \mathrm{MMA}$, the profiles were similar to the ones observed with $5 \mathrm{wt} \%$ of MMA, according to the data results in Fig. 15(b). However, since this reaction has a higher concentration of MMA, the retarding effect caused by this monomer was higher; as a consequence, the period for volume decrease was prolonged. Interestingly, while $5 \mathrm{wt} \%$ of MMA caused a decrease in the droplets volume of $9 \%$ until total consumption of this monomer, the volume of the droplets decreased only $5 \%$ of the initial volume when $10 \mathrm{wt} \%$ of MMA was used in the copolymerization. These data may, however, be affected by small inaccuracies of measurement, as already discussed.

The evolution of the droplets volume as a function of the PVC conversion, Fig. 15(c), providing similar profiles in respect to those observed in other homopolymerizations (Castor et al., 2015, 2016) and copolymerizations presented in this work. A high volume decrease can be observed the beginning of the gel effect, when the volume remains constant (or even presents a smooth increase) until the beginning of the vitreous effect (or a total consumption of the monomer phase within the droplets). Then, the droplets/particles volume decreases smoothly until the end of the copolymerization. The final volume should be defined in terms of the porosity characteristics desired by the manufacturer.

The evolution of droplet morphology observed with $10 \mathrm{wt} \%$ of MMA was similar to the one observed with $5 \mathrm{wt} \%$ of MMA, see Fig. 16. The schematic illustration, shown in Fig. 17, shows that the internal composition of the core is mainly composed of vinyl chloride. It is assumed that the part of the PMMA chains in the copolymerization grows on the droplet surface due to the grafting process with the PVA chains. The growth of the core is assumed to occur due to the diffusive flux of the vinyl chloride during the increase in concentration of PMMA between the droplet surface and the core as a consequence of the not-solubility of PMMA in VCM.

Assuming that the proposed interpretation is correct, the kinetic model of the MMA/VCM copolymerization can be very different from the homopolymerization of VCM through the formation of an additional thermodynamic phase.

\section{Conclusions}

The implementation of Raman spectroscopic technique has been successful for monitoring suspension homopolymerizations of monomers MMA and VCM as well as the MMA/VCM copolymerization. Raman spectroscopy was shown to be a powerful tool to monitor polymerization reactions, being sensitive to the usual variations of the most important process variables, such as mixture of monomers, the initiator type, initiator concentration, mixture of initiators and the reaction temperature. It was also shown that the selection of an adequate internal reference allowed for the successful monitoring of the monomer conversion with the proposed Raman technique. The technique was also able to determine the evolution of the composition in a copolymerization process, since characteristic bands of the double bonds of the monomers do not overlap, as well as their respective internal references used for normalization of the conversion data.

A very interesting result is that, among the many variations imposed on the copolymerization system (type of initiator and initial composition of the reactant mixture), an increasing of the process temperature was the most significant one. Thus, the possible production of MMA/VCM copolymers should probably be conducted at higher temperatures. It was also possible to relate the reaction kinetics with the evolution of the droplets volume during both the homopolymerizations and copolymerizations. It was shown that the volume changes are not directly affected by the conversion, and other relevant effects maintain constant volume for long conversion ranges. Finally, our findings showed the formation of a distinctive structure in the MMA/VCM copolymerization probably formed by a separate core of VCM from the PMMA formation, whose phenomenon greatly differs from the homopolymerization of VCM and has never been described before.

\section{Acknowledgments}

The authors thank CNPq (Conselho Nacional de Desenvolvimento Científico e Tecnológico, Brazil) for scholarships and financial support. The authors also thank INP-ENSIACET (part of Toulouse University) and the CNRS (Centre National de la Recherche Scientifique) for financial support.

\section{References}

Anon, 2011. Pvc Production Profitability. Report, Deloitte Touche Tohmatsu Limited (DTTL), London - UK.

Bally, F., Serra, C.A., Hessel, V., Hadziioannou, G., 2010. Homogeneous polymerization: benefits brought by microprocess technologies to the synthesis and production of polymers. Macromol. React. Eng. 4 (9-10), 543561.

Bayer, T., Pysall, D., Wachsen, O., 2000. Microreaction Technology: Industrial Prospects, vol. 4. Springer Berlin Heidelberg, Berlin (Ch. Micro mixing effects in continuous radical polymerization, IMRET 3: Proceedings of the Third International Conference on Microreaction Technology, pp. 165-170)

Benbachir, M., Benjelloun, D., 2001. Investigation of free radical polymerization using diperoxyesters as bifunctional initiators. Polymer 42 (18), 7727-7738.

Benson, R.S., Ponton, J.W. 1993. Process miniaturization - a route to total environmental acceptability? Trans. Ind. Chem. Eng. 71 (A2), 160-168.

Bichuch, N.A., Ganyukhina, T.G., Semchikov, Y.D., 2003. Specific features of suspension copolymerization of vinyl chloride with methyl methacrylate. Russian J. Appl. Chem. 76 (4), 607-609.

Bodoc, M.D., Prat, L., Xuereb, C., Gourdon, C., Lasuye, T., 2012. Online monitoring of vinyl chloride polymerization in a microreactor using raman spectroscopy. Chem. Eng. Technol. 35 (4), 705-712.

Bowden, M., Donaldson, P., Gardiner, D.J., Birnie, J., Gerrard, D.L., 1991. Monitoring polyvinyl chloride degradation using raman microline. Anal. Chem. 63 (24), 2915-2918.

Brandrup, J., Immergut, E.H., Grulke, E.A., Abe, A., Bloch, D.R., 1999. . Polymer Handbook, 4th ed., vol. 2. John Wiley \& Sons, Canada.

Burgess, R., 2005. Manufacture and Processing of PVC. Elsevier Applied Science Publishers, London.

Castor, C., Pontier, A., Durand, J., Pinto, J., Prat, L., 2015. Real time monitoring of the quiescent suspension polymerization of methyl methacrylate in microreactors part 1 . A kinetic study by raman spectroscopy and evolution of droplet size. Chem. Eng. Sci. 131, 340-352.

Castor, C., Pontier, A., Durand, J., Pinto, J., Prat, L., 2016. Real time monitoring of the quiescent suspension polymerization of vinyl chloride in microreactors - part 2. a kinetic study by raman spectroscopy and evolution of droplet size. Chem. Eng. Sci. 145, 279-293.

Cerna, J.R., Morales, G., Eyler, G.N., Canizo, A.I., 2002. Bulk polymerization of styrene catalyzed by bi- and trifunctional cyclic initiators. J. Appl. Polym. Sci. 83, 1-11.

Chang, Z., Liu, G., Fang, F., Tian, Y., Zhang, Z., 2004. gamma-ray-initiated dispersion polymerization of PMA in microreactor. Chem. Eng. J. 101 (1-3), 195-199.

Edwards, H., Johal, K., Johnson, A., 2006. Ft-raman spectroscopic monitoring of the group-transfer polymerisation of methyl methacrylate. Vibrat. Spectrosc. 41, 160-169.

Emmer, E.J., Bankoff, S.G., 1954. Suspension copolymerization of vinyl chloride and vinyl acetate. Ind. Eng. Chem. 46 (4), 673-675.

Fernandes, P., 2010. Miniaturization in biocatalysis. Int. J. Mol. Sci. 11 (3), 858-879.

Fityani-Trimm, S., Dhib, R., Penlidis, A., 2003. Free radical polymerization of styrene with a new tetrafunctional peroxide initiator. Macromol. Chem. Phys. 204 (3), 436-442.

Flory, P.J., 1953. Principles of Polymer Chemistry. Cornell University Press, New York.

Galhardo, E., Franco, C., Lona, L., 2013. Bifunctional initiators on the polymerization of vinyl acetate. J. Appl. Polym. Sci. 127 (3), 1711-1716.

Gorges, R., Meyer, S., Kreisel, G., 2004. Photocatalysis in microreactors. J. Photochem. Photobiol., A: Chem. 167 (2-3), 95-99.

Gulari, E., McKeigue, K., Ng, K.Y.S., 1984. Raman and FTIR spectroscopy of polymerization: bulk polymerization of methyl methacrylate and styrene. Macromolecules 17 (9), 1822-1825.

Iwasaki, T. Yoshida, J., 2005. Free radical polymerization in microreactors, significant improvement in molecular weight distribution control. Macromolecules 38 (4), 1159-1163.

Jensen, K.F., 2001. Microreaction engineering - is small better? Chem. Eng. Sci. 56 (2), 293-303.

Joyner, P., Glockler, G., 1952. The raman effect of vinylidene chloride. J. Chem. Phys. 20 (2), 302-306. 
Kamio K., Tadasa T., Halwzaki T., 1970. Process for Preparing Vinyl Chloride/ ethylene Copolymers. PATENT US-3501440 A

Kang, L., Chung, B., Langer, R., Khademhosseini, A., 2008. Microfluidics for drug discovery and development: from target selection to product lifecycle management. Drug Disc. Today 1, 1-13.

Kiwi-Minsker, L., Renken, A., 2005. Microstructured reactors for catalytic reactions. Catal. Today $110,2-14$.

Koenig, J.L., 1999. Spectroscopy of Polymers. Elsevier, New York.

Kitamura H., Koyanagi S., Sonegawa S., 1973. Methods for preparing graft polymers and resin compositions, PATENT US-3717688 A.

LaVision, 2006. DaVis StrainMaster Software Manual 7.1. GmbH, Alemanha, Gottingen.

Lerou, J.J., Harold, M.P., Ryley, J., O’Brien, J.A.T.C., Johnson, M., Perrotto, J., Blaisdell, C. T., Rensi, T.A., Nyquist, J., 1996. Microfabricated minichemical systems: technical feasibility. In: Ehrfeld, W. (Ed.), Microsystem Technology for Chemical and Biological Microreactors, vol. 132. DECHEMA Monographs, Verlag Chemie, pp. 51-69.

Leroyer, L., Prat, L., Cabassud, M., Gourdon, C., Dechy-Cabaret, O., Barthes, M., Camus, P., Hattou, S., 2013. Transposition of a triphosgene-based process for pharmaceutical development: from $\mathrm{mg} \mathrm{h}^{-1}$ to $\mathrm{kg} \mathrm{h}^{-1}$ of an unsymmetrical urea. Green Process. Synth. 2 (3), 239-250.

Liebman, S.A., Foltz, C.R., Reuwer, J.F., Obremski, R.J., 1971. Laser raman studies of poly(vinyl chloride). Macromolecules 4 (1), 134-138.

Lipiecki, F., Maroldo, S., Shenai-Khatkhate, D., Ware, R., 2008. Purification Process Using Microchannel Devices. PATENT US-12/215,827.

Lipiecki, F., Maroldo, S., Shenai-Khatkhate, D.V., Ware, R.A., 2009. Method of Preparing Organometallic Compounds Using Microchannel Devices. PATENT US-20090023940 A1.

Macho, V., Kralik, M., Micka, M., Komora, L., Bakos, D., 1998. Simultaneous statistical suspension copolymerization of vinyl chloride with butyl acrylate and grafting on poly(butyl acrylate). J. Appl. Polym. Sci. 68 (4), 649-656.

Maddans, W., 1977. Some applications of raman spectroscopy in structural studies on poly(vinyl chloride). J. Macromol. Sci., Part B: Physics 14 (1), 87-100.

Mahadevan, M., Lee, S., D., S.V., O., M., Hajri, E.A., Choi, K.Y., 2016. Heterogeneous catalytic polymerization of ethylene in microtubular reactor systems. Chem. Eng. Technol. 39(2), 293-300.

Martyak, N.M., 2010. Process for the Polymerization of Vinyl Chloride.

Marvel, C.S., Jones, G.D., Mastin, T.W., Schertz, G.L., 1942. The structure of copolymers of vinyl chloride and vinyl acetate. J. Am. Chem. Soc. 64 (10), 2356-2362.

Massignani, M., Lomas, H., Battaglia, G., 2010. Modern Techniques for Nano- and Microreactors/-reactions, vol. 229. Springer Berlin Heidelberg (Ch. Polymersomes: A Synthetic Biological Approach to Encapsulation and Delivery, pp. 115-154).

McCreery, R.L., 2000. Raman Spectroscopy for Chemical Analysis, vol. 157. John Wiley \& Sons, New York.

McNeill, I.C., Straiton, T., 1977. Copolymerization of methylmethacrylate with 36clvinylchloride. Eur. Polym. J. 13 (1), 17-18.

Müllner, S., Albert, W., 1967. Process for Preparing Vinyl Chloride Polymers.

Nass, I., Leonard, I., 1998. Encyclopedia of PVC - Volume 1, Resin Manufacture and Properties. CRC Press, New York - EUA.

Nielsen, C.A., Chrisman, R.W., LaPointe Jr., R.E., 2002. Novel tubing microreactor for monitoring chemical reactions. Anal. Chem. 74 (13), 3112-3117. T.E.M..
Pattekar, A., Kothare, M., 2004. A microreactor for hydrogen production in micro fuel cell applications. J. Microelectromech. Syst. 13 (1), 7-18.

Port, W.P., Jordan, E.F., Palm, W.E., Witnauer, L.P., Hansen, J.E., Swern, D., 1955 Polymerizable derivatives of long-chain fatty acids. Indust. Eng. Chem. 47 (3), 472-480.

Reiter W.M., Reventas A.A.,1973. Method for Suspension Polymerization of Vinyl Chloride. PATENT US-3757001 A.

Richard, R., Dubreuil, B., Thiebaud-Roux, S., Prat, L., 2013. On-line monitoring of the transesterification reaction carried out in microreactors using near infrared spectroscopy. Fuel 104, 318-325.

Salic, A., Tusek, A., Zelic, B., 2012. Application of microreactors in medicine and biomedicine. J. Appl. Biomed. 10, 137-153.

Scorah, M.J., Dhib, R., Penlidis, A., 2004. Free-radical polymerization of methy methacrylate with a tetrafunctional peroxide initiator. J. Polym. Sci.: Part A: Polym. Chem. 42, 5647-5661.

Sheng, W., Wu, J.-Y., Shan, G.-R., Huang, Z.-M., Weng, Z.-X., 2004. Free-radical bulk polymerization of styrene with a new trifunctional cyclic peroxide initiator. J Appl. Polym. Sci. 94, 1035-1042.

Sielfeld G. 1984. Process for the Production of Polymer and Copolymers of Vinyl Chloride by Suspension Polymerization and Their Use as Viscosity Reducing Agents in Plastisol Processing. PATENT US-4472561 A.

Soljic, L., Penovic, T., Jukic, A., Janovic, Z., 2009. Kinetic study of free radical copolymerization of dodecyl methacrylate and styrene using diperoxide initiator. AIDIC Conf. Ser. 9, 283-292.

SOLVAY, 1971. Graft Copolymerization of Vinyl Chloride and Epichlorohydrine Polymers.

SOLVAY, 1975. Production of Non-Stick Vinyl Chloride Polymer Compositions.

Starnes, W.H., Zaikov, V.G., Chung, H.T., Wojciechowski, B.J., Tran, H.V., Saylor, K., 1998. Intramolecular hydrogen transfers in vinyl chloride polymerization: routes to doubly branched structures and internal double bonds. Macromolecules 31, 1508-1517.

Sun, J., Ju, J., Ji, L., Zhang, L., Xu, N., 2008. Synthesis of biodiesel in capillary microreactors. Ind. Eng. Chem. Res. 47 (5), 1398-1403.

Walsh, D.J., Cheng, G.L., 1982. The in situ polymerization of vinylchloride in poly (butyl acrylate). Polymer 23 (13), 1965-1970.

Wegeng, R.W., Call, C.J., Drost, M.K., 1996. Chemical system miniaturization. In: Proceedings of the AIChE Spring National Meeting. New Orleans, pp. 1-13 (Feb. 1996).

Williams, G.D., 1970. Graft Copolymerization of Methyl Methacrylate Onto Polyvinyl Chloride. PATENT US-3,504,053.

Willis, H.A., Zichy, V.J.I., Hendra, P.J., 1969. The laser-raman and infra-red spectra of poly(methyl methacrylate). Polymer 10, 737-746.

Yong-Zhong, B., Zhi-Xue, W., Zhi-Ming, H., Zu-Ren, P., 2000. Synthesis of chemically crosslinked poly(vinyl chloride) by vinyl chloride-divinyls suspension copolymerization. Eur. Polym. J. 36, 981-986.

Yonkers, P.K., Keller, W.F., Ferry, D., Altscher, S., 1971. Solution Grade PVCCopolymers Prepared by Suspension Polymerization Exhibiting Enhanced Light Stability and Low Haze.

Yuan, J., Pan, M., Wang, X., Zhang, L., 2007. Dynamic mechanical rheological and morphological studies of polyacrylate-graft-poly (vinyl chloride) suspension resin. Polym. Eng. Sci. 47 (7), 996-1003.

Zhang, X., Stefanick, S., Villani, F.J., 2004. Application of microreactor technology in process development. Organic Process Res. Develop. 8, 455-460. 